\title{
Neuroimaging studies of working memory: A meta-analysis
}

\author{
TOR D. WAGER and EDWARD E. SMITH \\ University of Michigan, Ann Arbor, Michigan
}

\begin{abstract}
We performed meta-analyses on 60 neuroimaging (PET and fMRI) studies of working memory (WM), considering three types of storage material (spatial, verbal, and object), three types of executive function (continuous updating of WM, memory for temporal order, and manipulation of information in WM), and interactions between material and executive function. Analyses of material type showed the expected dorsal-ventral dissociation between spatial and nonspatial storage in the posterior cortex, but not in the frontal cortex. Some support was found for left frontal dominance in verbal WM, but only for tasks with low executive demand. Executive demand increased right lateralization in the frontal cortex for spatial WM. Tasks requiring executive processing generally produce more dorsal frontal activations than do storage-only tasks, but not all executive processes show this pattern. Brodmann's areas (BAs) 6, 8, and 9, in the superior frontal cortex, respond most when WM must be continuously updated and when memory for temporal order must be maintained. Right BAs 10 and 47, in the ventral frontal cortex, respond more frequently with demand for manipulation (including dual-task requirements or mental operations). BA 7, in the posterior parietal cortex, is involved in all types of executive function. Finally, we consider a potential fourth executive function: selective attention to features of a stimulus to be stored in WM, which leads to increased probability of activating the medial prefrontal cortex (BA 32) in storage tasks.
\end{abstract}

Working memory (WM), a system for actively maintaining and manipulating information, has been one of the most studied topics in cognitive psychology and cognitive neuroscience. It is fundamental to the performance of many cognitive tasks and day-to-day activities: imagining how an object might look from a different perspective, remembering a phone number while taking something out of the oven, solving a math problem "in your head," or planning the next move in a chess game, to give just a few examples. WM is sometimes conceptualized as an active workspace because it is closely linked with the voluntary allocation of attention. The study of WM is central to understanding how memory and thought work.

\section{Models of Working Memory}

Baddeley (1992) and colleagues have given one of the clearest conceptualizations of WM. They proposed two basic subsystems for maintaining information-the phonological loop and the visuospatial sketch pad, for remembering verbal and visual information, respectively. These subsystems are further subdivided into pas-

This research was supported by a National Institute of Mental Health grant to the second author and a National Science Foundation Graduate Research Fellowship to the first author. Thanks to Susan Reading and David Lessens for preparing the database of coordinates and to John Jonides, Ching-Yune Sylvester, and Amanda Thomas for suggestions on the manuscript. Correspondence concerning this article should be addressed to T. D. Wager, Department of Psychology, Columbia University, 1190 Amsterdam Ave., New York, NY 10027 (e-mail: tor@ paradox.psych.columbia.edu). sive storage and active rehearsal mechanisms. Manipulation of information held in WM is accomplished by a third, central executive system. Most broad architectures of human cognition incorporate some version of this framework. In this meta-analysis, we are concerned with the neural basis of WM.

\section{Controversies on the Organization of the Frontal Lobes}

Some of the earliest neuroimaging studies of WM addressed questions raised in part by Baddeley's (1992) framework-particularly, how the putative components of WM map onto brain systems and whether patterns of brain activation respect the distinctions between types of WM apparent in behavioral studies.

Organization by material type. One of the major dimensions along which WM systems may be subdivided is the type of material stored in WM. Three types of material have been most commonly studied: verbal, spatial, and object information. Verbal information includes words, letters, or other material that is primarily coded linguistically and is likely to be maintained by a rehearsal process involving a subvocal sequential generation of memory items. Spatial information includes information about the spatial positions of stimuli. Object information includes storage of nonspatial visual features or object identity.

We tested three hypotheses about the organization of WM by material type. One organizational principle, based on monkey and human studies (e.g., Funahashi, Chafee, \& Goldman-Rakic, 1993; Smith \& Jonides, 1999; Wilson, 
Scalaidhe, \& Goldman-Rakic, 1993), is that there are dorsal and ventral processing (and memory) streams for spatial and object information, respectively. In the posterior cortex, the dorsal stream projections feed forward from the extrastriate cortex to the inferior parietal lobule and the intraparietal sulcus (IPS). The ventral stream extends from the extrastriate cortex to the inferior surface of the frontal pole. Anterior areas in both streams contain neurons with larger and more complex receptive fields (see, e.g., Rockland, 2002) and show greater modulation by executive functions. In the frontal cortex, spatial WM activates the superior dorsolateral prefrontal cortex (DLPFC) or the superior frontal sulcus (SFS; Courtney, Petit, Haxby, \& Ungerleider, 1998), whereas object WM, it is suggested, increases neural activity in several mid- and inferior frontal regions.

A second, prevalent hypothesis of material-type effects in the frontal cortex is that verbal WM is left lateralized (e.g., Reuter-Lorenz et al., 2000; Smith \& Jonides, 1999), presumably because it involves a subvocal verbal rehearsal process for which Broca's area, in the left frontal operculum, is critical. A third, related proposal is that spatial WM is right lateralized in the frontal cortex, whereas object WM is left lateralized. Several groups (e.g., McCarthy et al., 1996; Reuter-Lorenz et al., 2000; Smith et al., 1995) have found evidence supporting this view, although other studies have not shown this effect (e.g., Courtney, Ungerleider, Keil, \& Haxby, 1996).

Organization by process type. The issue of specialization by storage material type is complicated by the fact that maintaining spatial, verbal, and object memory likely requires different types of rehearsal strategies and processes (see, e.g., Courtney et al., 1998). Thus, specialization according to process may cause apparent differences in brain activation among material types.

Reflecting on this complexity, several groups (D'Esposito et al., 1998; Owen, 1997, 2000) have provided evidence that a dorsal-ventral gradient exists in the frontal cortex that has to do not with the distinction among material types, but with types of processing. According to this view, the superior frontal cortex is involved in monitoring and manipulation of information (or generalized executive processing), whereas the ventral frontal cortex is important for rehearsal during simple storage. As will be seen, our results generally agree with the dorsalexecutive ventral-storage hypothesis, but only for particular types of executive process. We propose a finer grained classification of various executive processes that commonly fall under the rubric of manipulation and suggest that certain executive processes are associated with dorsal frontal activity and others with ventral frontal activity.

\section{Meta-Analysis as a Research Tool in Neuroimaging}

A number of brain-imaging studies have provided evidence regarding these issues, but different studies support different types of organization. One problem is that studies typically rely on the logic of double dissociation:
In an imaging study, Task 1 activates Area A, but not B, and Task 2 activates B, but not A. This logic has traditionally been considered to be strong evidence that separate mechanisms implement Tasks 1 and 2, but it depends on two essential assumptions: (1) Each task truly isolates the processes under investigation (e.g., the pattern of activation does not reflect a dissociation between $\mathrm{C}$ and D), and (2) one can tell with some certainty if a task does not activate an area. In most individual imaging studies, both of these assumptions are violated. WMimaging studies often control for basic visuomotor aspects of the task but do not control all aspects of executive demand. Second, it is difficult to conclude from a single study that any given area was truly not activated: Low signal-to-noise ratio, motion artifacts, other physiological artifacts that vary by task, and relatively small sample sizes are some factors that make it challenging to definitively demonstrate that an area was not affected by a particular task. Meta-analysis can be useful in this situation because it provides a concise way to summarize a large number of studies. It can help to resolve some of the problems mentioned above by reducing the impact of confounds in individual studies, and it can provide more data on the reliability of activation and absence of activation in particular brain regions.

The present meta-analyses were designed to summarize neuroimaging studies of WM to date. The analyses test whether existing findings in the literature are supported across studies and whether, when data from a large number of studies are examined, new findings emerge. The data are reported coordinates of the most activated voxels (peaks) within contiguous areas of activation from 60 studies that met our selection criteria (see the Method section). We focused on testing for differences in regional activation based on both material type and executive requirements across studies.

A number of previous meta-analyses and reviews of WM have been performed; although valuable, the inferences in these studies have been made largely on qualitative patterns of results (Chein, Fissell, Jacobs, \& Fiez, 2002; Courtney et al., 1998; D'Esposito et al., 1998; Owen, 1997; Owen et al., 1998; Smith \& Jonides, 1999). In this article, we use two quantitative meta-analysis techniques: chi-square $\left(\chi^{2}\right)$ analy sis on reported Brodmann's areas (BAs) and cluster analysis (to provide data-driven definitions of functional regions) followed by chi-square analysis within clusters. These techniques allow us to examine regional brain specialization for types of materials stored in WM and types of putative executive functions. Each of these techniques will later be explained in detail.

\section{METHOD}

\section{Study Selection}

We analyzed 60 PET and fMRI studies of WM tasks published between 1993 and July 2002, listed in Table 1. Studies were identified by searches on two versions of Medline (Medsearch and Pubmed) and PsycInfo. Stud- 
ies were included if they (1) reported whole-brain comparisons of WM tasks in comparison with a control task that contained similar perceptual and motor requirements (i.e., no passive fixation baselines), (2) included healthy unmedicated subjects, and (3) reported standardized coordinates for activation foci in either Montreal Neurological Institute (MNI) or Talairach (Talairach $\&$ Tournoux, 1988) space. As in previous meta-analyses (Phan, Wager, Taylor, \& Liberzon, 2002; Wager, Phan, Liberzon, \& Taylor, 2003), we analyzed only positive WM activations, since deactivations have been reported inconsistently and are more difficult to interpret. Peak activation coordinates reported in each study were classified in two ways: (1) according to the BA classification provided by the Talairach Daemon (http://ric.uthscsa.edu/ projects/talairachdaemon.html) for each coordinate, after transformation to Talairach space from MNI space (using Matthew Brett's bilinear transformation, http:// www.mrc-cbu.cam.ac.uk/Imaging/; no coordinate was shifted more than $10 \mathrm{~mm}$ ), where appropriate, and (2) according to clusters, using a data-driven algorithm, described below. For material type analyses, we included only results from tasks that did not include any of the three major executive processes, as identified below.

\section{Classification of Peaks by Material Type and Executive Function}

Most neuroimaging studies of WM involve a variant of one of two common tasks: the $N$-back task (Cohen et al., 1997) and the item recognition task (Schumacher et al., 1996). Other, slightly less common tasks are variants of the continuous performance task (CPT; Carter et al., 1998) and self-ordered selection tasks (Petrides, 1991). The $N$-back task involves viewing a continuous stream of items (e.g., letters) and deciding whether each item matches the stimulus presented $n$ stimuli back, where $n$ is usually 2 or 3 . The item recognition task involves studying a memory set typically consisting of 1-6 items, maintaining the items during a delay (usually less than $10 \mathrm{sec}$ ), and responding to a probe item. The participant must determine whether the probe item was a member of the memory set.

Each of these types of tasks involves storage of information in WM but may or may not involve various types of executive process. We classified each peak coordinate reported according to the type of material to be remembered, with major categories of verbal, spatial, and object. Most of the tasks studied involved multiple executive functions but focused on a single type of material. Our analysis of the effects of material type excluded tasks that required active processing of information, in addition to storage.

In separate analyses, we identified three types of operations commonly performed on items stored in WM, and we classified each peak coordinate in each study we reviewed according to whether it required that operation. The operations are (1) whether the task required manipulation of information stored in WM concurrent with storage of information or required only storage (examples are arithmetic operations on items in WM and mental rotation), (2) whether the task required memory for the order of the items in memory or simply their identities, and (3) whether updating of WM was continuous (items continuously added and deleted from WM) or discrete (a new memory set for each trial, as in the item recognition task). Order and updating are each identified by a single characteristic of the task. An example of order memory is an item recognition task in which the probe involves remembering information about the positions of the items in a sequence, as opposed to simply requiring memory of the identities of stimuli. One example of continuous updating is the $N$-back task. Another is a task in which participants must remember the last four items in a continuous stream, forgetting old items as new ones are added. Manipulation is more complex to define, since it encompasses diverse paradigms that involve operating on information while storing the same or other information in WM. The operation span task, for example, requires maintenance of verbal information while mathematical operations are performed (Smith et al., 2001). Other manipulation tasks involve similar dual-task requirements (see, e.g., Bunge, Klingberg, Jacobsen, \& Gabrieli, 2000) or, for example, arithmetically operating on numbers in WM (Landro et al., 2001; Tsukiura et al., 2001).

These three operations are not the only ones that have been proposed as executive processes. In particular, inhibition and attention switching are often thought of as critical executive processes (Jonides, Badre, Curtis, Thompson-Schill, \& Smith, 2002; Miyake, Friedman, Emerson, Witzki, \& Howerter, 2000; Rubenstein, Meyer, \& Evans, 2001; Smith \& Jonides, 2003; Sylvester et al., 2003). We chose the operations we did because each task could be unambiguously coded on the basis of the criteria we described above. Furthermore, the classes of executive processes we defined are conceptually independent: Each can occur independently of the others, although other underlying operations may be shared among the processes.

A fourth potential kind of operation is selective attention. Many early neuroimaging studies compared WM for various material types (e.g., faces and spatial locations) using two-dimensional (2-D) items (e.g., Courtney et al., 1996; Smith et al., 1995). These items contained identical visual information-for example, faces at different locations on a computer screen - and participants were asked to remember one feature (e.g., location) and ignore the other. In these studies, although the stimuli were matched, the task required something more than simple storage of information-namely, selective attention to one stimulus attribute. In the present metaanalysis, we define selection as the active maintenance of one attribute of a multidimensional stimulus, as opposed to maintenance of stimuli with only one relevant attribute. It may be argued that all stimuli are multidimensional in the sense that they inherently possess 
Table 1

Studies Analyzed

\begin{tabular}{|c|c|c|c|c|c|c|c|c|c|}
\hline Authors & Year & Scan & Subjects & Design & Material & $\mathrm{U}$ & $\mathrm{M}$ & $\mathrm{O}$ & $\mathrm{SA}$ \\
\hline Barch et al. & 1997 & fMRI & 11 & block & verbal & & & & \\
\hline \multirow[t]{2}{*}{ Belger et al. } & 1998 & fMRI & 18 & block & object & & & & \\
\hline & & & 18 & block & spatial & & & & \\
\hline Bor et al. & 2001 & PET & 10 & block & spatial & & & $\mathrm{x}$ & N/A \\
\hline Braver et al. & 2001 & fMRI & 28 & block & N/A & $\mathrm{x}$ & & $\mathrm{x}$ & N/A \\
\hline Braver \& Bongiolatti & 2002 & fMRI & 21 & block & verbal & & & & \\
\hline Braver et al. & 1997 & fMRI & 8 & block & verbal & $\mathrm{x}$ & & $\mathrm{x}$ & N/A \\
\hline \multirow[t]{3}{*}{ Bunge et al. } & 2000 & fMRI & 8 & block & verbal & & & $\mathrm{x}$ & N/A \\
\hline & & & 8 & block & verbal & & & $\mathrm{x}$ & N/A \\
\hline & & & 8 & block & verbal & & $\mathrm{x}$ & $\mathrm{x}$ & \\
\hline Callicott et al. & 1999 & fMRI & 9 & block & verbal & $\mathrm{x}$ & & $\mathrm{x}$ & N/A \\
\hline Casey et al. & 1998 & fMRI & 24 & block & spatial & $\mathrm{x}$ & & $\mathrm{x}$ & N/A \\
\hline Chein \& Fiez & 2001 & fMRI & 12 & ER & verbal & & & $\mathrm{x}$ & N/A \\
\hline Clark et al. & 2000 & PET & 10 & block & verbal & $\mathrm{x}$ & & & N/A \\
\hline Cohen et al. & 1997 & fMRI & 10 & block & verbal & $\mathrm{x}$ & & $\mathrm{x}$ & N/A \\
\hline Collette et al. & 1999 & PET & 7 & block & verbal & & N/A & N/A & \\
\hline Cornette, Dupont, Bormans, et al. & 2001 & PET & 14 & block & object & $\mathrm{x}$ & & $\mathrm{x}$ & N/A \\
\hline \multirow{2}{*}{ Cornette, Dupont, Salmon, \& Orban } & 2001 & PET & 9 & block & object & $\mathrm{x}$ & & $\mathrm{x}$ & N/A \\
\hline & & & 9 & block & object & & & & \\
\hline \multirow[t]{2}{*}{ Courtney et al. } & 1996 & PET & 16 & block & object & & & & $\mathrm{x}$ \\
\hline & & & 16 & block & spatial & & & & $\mathrm{x}$ \\
\hline Courtney et al. & 1997 & fMRI & 8 & block & object & & & & \\
\hline \multirow{2}{*}{ Crosson et al. } & 1999 & fMRI & 12 & block & verbal & & N/A & & \\
\hline & & & 12 & block & verbal & & & & \\
\hline Curtis et al. & 2000 & PET & 8 & block & object & $\mathrm{x}$ & & & N/A \\
\hline \multirow[t]{3}{*}{ Dade et al. } & 2001 & PET & 12 & block & N/A & $\mathrm{x}$ & & $\mathrm{x}$ & N/A \\
\hline & & & 12 & block & object & $\mathrm{x}$ & & $\mathrm{x}$ & N/A \\
\hline & & & 12 & block & odor & $\mathrm{x}$ & & $\mathrm{x}$ & N/A \\
\hline de Fockert et al. & 2001 & fMRI & 6 & block & verbal & & & $\mathrm{x}$ & N/A \\
\hline \multirow[t]{2}{*}{ D'Esposito et al. } & 1998 & fMRI & 24 & ER & spatial & $\mathrm{x}$ & & $\mathrm{x}$ & N/A \\
\hline & & & 24 & ER & verbal & $\mathrm{x}$ & & $\mathrm{x}$ & N/A \\
\hline Diwadkar et al. & 2000 & fMRI & 18 & block & spatial & $\hat{x}$ & & & N/A \\
\hline Druzgal \& D'Esposito & 2001 & fMRI & 9 & block & object & $\mathrm{x}$ & & $\mathrm{x}$ & N/A \\
\hline Grady et al. & 1998 & PET & 13 & block & object & & & & \\
\hline \multirow[t]{2}{*}{ Haut et al. } & 2000 & PET & 6 & block & verbal & $\mathrm{x}$ & & & N/A \\
\hline & & & 6 & block & verbal & $\mathrm{x}$ & & & N/A \\
\hline Honey et al. & 2000 & fMRI & 20 & block & verbal & $\mathrm{x}$ & & $\mathrm{x}$ & N/A \\
\hline Jiang et al. & 2000 & fMRI & 6 & block & object & & & & \\
\hline Jonides et al. & 1998 & PET & 12 & block & verbal & & & & \\
\hline Jonides et al. & 1993 & PET & 18 & block & spatial & & & & \\
\hline Klingberg et al. & 1997 & PET & 9 & block & object & & & & $\mathrm{x}$ \\
\hline LaBar et al. & 1999 & fMRI & 11 & block & verbal & $\mathrm{x}$ & & $\mathrm{x}$ & N/A \\
\hline Landro et al. & 2001 & fMRI & 12 & block & verbal & $\mathrm{x}$ & $\mathrm{x}$ & & N/A \\
\hline \multirow[t]{2}{*}{ Marshuetz et al. } & 2000 & fMRI & 12 & block & verbal & & & & \\
\hline & & & 12 & block & verbal & & & $\mathrm{x}$ & N/A \\
\hline \multirow[t]{2}{*}{ McCarthy et al. } & 1996 & fMRI & 10 & ER & object & N/A & & & \\
\hline & & & 10 & ER & spatial & N/A & & & \\
\hline Mecklinger et al. & 2000 & fMRI & 12 & ER & object & & & & \\
\hline & & & 16 & ER & object & & & & $\mathrm{x}$ \\
\hline & & & 16 & ER & spatial & & & & $\mathrm{x}$ \\
\hline Mitchell et al. & 2000 & fMRI & 12 & block & object & & & & $\mathrm{x}$ \\
\hline & & & 12 & block & spatial & & & & $\mathrm{x}$ \\
\hline Nystrom et al. & 2000 & fMRI & 10 & block & object & $\mathrm{x}$ & & $\mathrm{x}$ & N/A \\
\hline & & & 10 & block & spatial & $\mathrm{x}$ & & $\mathrm{x}$ & N/A \\
\hline & & & 7 & block & spatial & $\mathrm{x}$ & & $\mathrm{x}$ & N/A \\
\hline & & & 8 & block & object & $\mathrm{x}$ & & $\mathrm{x}$ & N/A \\
\hline & & & 8 & block & verbal & $\mathrm{x}$ & & $\mathrm{x}$ & N/A \\
\hline Owen & 2000 & PET & 8 & block & verbal & & & $\mathrm{x}$ & N/A \\
\hline & & & 8 & block & verbal & & $\mathrm{x}$ & $\mathrm{x}$ & N/A \\
\hline Owen et al. & 1996 & PET & 16 & block & spatial & $\mathrm{x}$ & $\mathrm{x}$ & & N/A \\
\hline & & & 16 & block & spatial & & & & \\
\hline & & & 16 & block & spatial & & & & \\
\hline Owen et al. & 1999 & PET & 5 & block & spatial & $\mathrm{x}$ & & $\mathrm{x}$ & N/A \\
\hline & & & 5 & block & spatial & & & $\mathrm{x}$ & N/A \\
\hline Owen et al. & 1998 & fMRI & 6 & block & object & $\mathrm{x}$ & & $\mathrm{x}$ & N/A \\
\hline & & & 6 & block & spatial & $\mathrm{x}$ & & $\mathrm{x}$ & N/A \\
\hline Paulesu et al. & 1993 & PET & 6 & block & verbal & & & & \\
\hline Perlstein et al. & 2002 & fMRI & 10 & ER & object & & & & \\
\hline
\end{tabular}


Table 1 (Continued)

\begin{tabular}{|c|c|c|c|c|c|c|c|c|c|}
\hline Authors & Year & Scan & Subjects & Design & Material & $\mathrm{U}$ & M & $\mathrm{O}$ & $\mathrm{SA}$ \\
\hline \multirow[t]{2}{*}{ Petit et al. } & 1998 & fMRI & 12 & block & object & & & & $\mathrm{x}$ \\
\hline & & & 12 & block & spatial & & & & $\mathrm{X}$ \\
\hline \multirow[t]{2}{*}{ Petrides et al. } & 1993 & PET & 10 & block & verbal & $\mathrm{X}$ & & & N/A \\
\hline & & & 10 & block & verbal & $\mathrm{X}$ & & & N/A \\
\hline Pollmann \& von Cramon & 2000 & fMRI & 9 & ER & object & & & & \\
\hline Rama et al. & 2001 & f MRI & 8 & block & verbal & $\mathrm{X}$ & & $\mathrm{x}$ & N/A \\
\hline \multirow[t]{2}{*}{ Reuter-Lorenz et al. } & 2000 & PET & 10 & block & spatial & & & & \\
\hline & & & 10 & block & verbal & & & & \\
\hline \multirow[t]{2}{*}{ Rowe \& Passingham } & 2001 & fMRI & 6 & ER & spatial & & & $\mathrm{X}$ & N/A \\
\hline & & & 6 & ER & spatial & & $\mathrm{X}$ & & N/A \\
\hline Rypma et al. & 1999 & fMRI & 6 & block & verbal & & & & \\
\hline Schumacher et al. & 1996 & PET & 8 & block & verbal & $\mathrm{x}$ & & $\mathrm{X}$ & N/A \\
\hline \multirow{2}{*}{ Smith et al. } & 2001 & PET & 12 & block & verbal & & $\mathrm{X}$ & $\mathrm{x}$ & N/A \\
\hline & & & 12 & block & verbal & & & $\mathrm{x}$ & N/A \\
\hline \multirow[t]{4}{*}{ Smith et al. } & 1996 & PET & 8 & block & spatial & $\mathrm{X}$ & & $\mathrm{x}$ & N/A \\
\hline & & & 8 & block & verbal & $\mathrm{X}$ & & $\mathrm{x}$ & N/A \\
\hline & & & 11 & block & verbal & & $\mathrm{X}$ & & N/A \\
\hline & & & 18 & block & spatial & & & & \\
\hline \multirow[t]{4}{*}{ Smith et al. } & 1995 & PET & 12 & block & object & & & & \\
\hline & & & 18 & block & object & & & & $\mathrm{X}$ \\
\hline & & & 18 & block & spatial & & & & \\
\hline & & & 18 & block & spatial & & & & $\mathrm{X}$ \\
\hline \multirow[t]{2}{*}{ Stern et al. } & 2000 & fMRI & 5 & block & object & & & & \\
\hline & & & 5 & block & object & & & $\mathrm{X}$ & N/A \\
\hline Thomas et al. & 1999 & fMRI & 6 & block & spatial & $\mathrm{x}$ & & $\mathrm{X}$ & $\mathrm{N} / \mathrm{A}$ \\
\hline \multirow[t]{3}{*}{ Tsukiura et al. } & 2001 & fMRI & 6 & block & verbal & & N/A & & \\
\hline & & & 6 & block & verbal & & & & \\
\hline & & & 6 & block & verbal & & $\mathrm{X}$ & & N/A \\
\hline Van der Linden et al. & 1999 & PET & 6 & block & verbal & $\mathrm{X}$ & & $\mathrm{X}$ & N/A \\
\hline Zurowski et al. & 2002 & PET & 8 & block & N/A & $\mathrm{X}$ & N/A & $\mathrm{X}$ & N/A \\
\hline
\end{tabular}

Note-Design types were classified as "block" for blocked designs and "ER" for event-related designs. One line appears per contrast; some studies involved more than one contrast or experiment. Blank entries in the right-hand columns indicate absence of an executive function. N/A indicates either that a classification was unclear (the contrast was excluded) or that, as for selective attention, the category did not apply and the contrast was not used. For selective attention, N/A values appear when the contrast involved other executive functions. U, continuous updating; M, manipulation; O, order memory; SA, selective attention.

multiple attributes, raising the possibility that processing any stimulus requires some degree of selective attention. However, 2-D stimuli used in WM studies are different from one-dimensional (1-D) stimuli in that two obvious salient features are potentially relevant and participants are typically asked to attend to each at different points in the study. These factors increase the demand for selective attention.

Selective attention for WM maintenance may be similar to the inhibition or selective attention required in Stroop-like tasks - both require the maintenance of a processing bias (e.g., "respond to colors"; Cohen, Dunbar, \& McClelland, 1990; Miller \& Cohen, 2001)—or it may be different, since the task explicitly requires memory. We wanted to determine empirically whether the demand for selective attention has any effect on WM activations, by comparing storage tasks that employ 2-D versus 1 -D stimuli, and whether selective attention effects produce activation changes similar to the other executive processes defined above.

\section{Cluster Analysis}

We performed cluster analysis - using the partitioning around medoids (pam) algorithm (see below), as imple- mented in S-plus - to provide data-driven classification of reported peaks into distinct anatomical regions. The advantage of using clustering methods is that the data determine what the brain regions are and which points fall within each region, rather than defining regions according to BA or some other arbitrary anatomical categorization scheme (e.g., left frontal/right frontal). Clustering algorithms use the natural separation between groups of peaks to define anatomical regions, find the anatomical centers of those regions, and indirectly, provide information about the spatial resolution across studies.

The pam algorithm (Kaufman \& Rousseeuw, 1987, 1990) was chosen as a clustering algorithm because it makes few assumptions about the distribution of peaks and the resulting shapes of clusters. It is similar in principle to the well-known $k$-means algorithm (e.g., MacQueen, 1967) —in both techniques, the number of clusters must be specified a priori-but pam has several important advantages that make it more robust than $k$-means. First, pam does not require an initial choice of starting estimates for cluster means. Second, $k$-means assumes spherical clusters with normal distributions, whereas spatial clusters in neuroimaging data are expected to follow the contours of the gyri and sulci. An important additional benefit is that 
the pam algorithm provides a quality index for clustering, allowing some principled choice of the number of clusters.

The pam algorithm works by finding representative objects (peaks), called medoids, that minimize the distance from each peak to the nearest medoid, as described by the objective function for the algorithm:

$$
\sum_{i=1}^{n} \min _{t=1, \ldots, k} d\left(i, m_{t}\right)
$$

In Equation 1, $d$ is the distance between peak $i$ and the medoid $m_{t}$ that is the closest to $i$. Once the medoids have been chosen, each peak is assigned membership in the cluster defined by the closest medoid.

The process of choosing medoids is accomplished in two steps. First, starting estimates for medoids are assigned one by one until $k$ medoids (one for each cluster) have been assigned. Each successive medoid is placed by selecting the peak that minimizes the objective function, given the previous medoid placements. After initial medoids have been chosen, the algorithm enters a swapping phase, in which medoid-peak pairs are examined and the peak that decreases the objective function the most (if any) becomes the new medoid. At the algorithm's completion, each medoid is the center-or more precisely, the representative peak-for a cluster.

Once the algorithm converges on a solution, a quality index of the solution for $k$ medoids can be calculated and compared with solutions for other $k$. The quality index is the average over all peaks $i=\{1 \ldots n\}$ in all clusters $t=$ $\{1 \ldots k\}$ of the following quantity: the average distance from the peak to other peaks in the nearest neighboring cluster minus the average distance to peaks in cluster $t$, divided by the greater of those two quantities. The resulting index value for each peak, called the silhouette index, varies between -1 and 1 , with high positive values signifying unambiguous cluster assignment, 0 signifying equidistance between two clusters, and negative values signifying that the peak is closer to the peaks of a neighboring cluster than to peaks of its own cluster.

We performed the clustering analysis twice, once for peaks in storage-only tasks and once for all peaks. The results of the first analysis were used as input regions for $\chi^{2}$ tests in the material type analysis, and the results of the second were used in the analysis of executive functions. The algorithm was run for $k$ between 2 and 25, and a value for $k$ was selected that maximized the average silhouette index while providing a reasonable number of brain areas on the basis of expectations derived from the literature. For example, the 2-cluster solution for these data often had a high quality index, signifying relatively unambiguous grouping into right and left hemispheres; however, this was deemed too anatomically general; instead, 11-cluster (for material type) and 15-cluster (for executive function) solutions were chosen. For material type, the 11-cluster solution had an average silhouette index (ASI) of .370, with a mean for solutions between 2 and 25 clusters of .348 and a standard deviation of .017. For executive functions, the chosen solution had an
ASI of .372, with a mean of .353 and a standard deviation of .019. Once cluster memberships were identified, $\chi^{2}$ analyses were performed on peaks within each cluster, to test for material type and executive specificity, as will be described below.

\section{Chi-Square Analysis}

For each cluster, we calculated two types of summary measures of activation: number/percentage of studies and number/percentage of peaks. For studies, a count was incremented in a region if the study reported at least one activation peak in that region. For peaks, the total number of peaks in the region across all the studies was counted. Both counting peaks and studies have associated advantages and disadvantages. Because of differences in data collection methods, smoothing parameters, and significance thresholds, there is an inherent imprecision in combining data from different studies. For example, studies that report many peaks, perhaps due to the application of a relatively small smoothing filter, would be overrepresented when one counts peaks. However, if studies of two conditions are being compared (e.g., passive storage and executive function) and activations occur in both conditions but activations are larger in area and magnitude for one condition (e.g., executive function), counting peaks may be sensitive to this difference, whereas counting studies may not (Phan et al., 2002).

Within each cluster, for both studies and peaks, we used $\chi^{2}$ analyses to test whether the distribution of peaks or studies falling within each region differed among conditions. We examined two types of conditions: type of material to be remembered (verbal, spatial, or object) and type of executive process (continuous updating, order memory, manipulation of information, and selective attention). Separate $\chi^{2}$ analyses were performed for each set of conditions, and expected values were based on the total number of peaks (or studies) reported in each condition, collapsing across regions, and the total number of activation peaks (or studies), collapsing across conditions. For example, in a peaks analysis, for each cluster we determined the number of peaks from verbal, spatial, and visual WM tasks falling within the cluster. Using the whole-brain peak counts for each material type to normalize the expected counts, we tested whether the proportions of peaks within the cluster differed significantly across material types (an example of the $\chi^{2}$ procedure described in the next section). A similar analysis using study counts was carried out for each cluster.

\section{Brodmann Area Analysis}

We used $\chi^{2}$ to analyze peaks within each BA in the same fashion. For example, the frequencies of 33 storage-only studies reporting activations in BA 9 were 1 of 10 studies for spatial WM, 9 of 14 for object WM, and 4 of 9 for verbal WM. Null-hypothesis expectations are based on the total studies reporting peaks within the region (14), multiplied by the proportion of total studies in each con- 
dition (10/33 for spatial, $14 / 33$ for object, and $9 / 33$ for verbal). The product yields an expected frequency of 14 total studies $*(10 / 33)=4.24$ for spatial study counts in BA 9. The computation is performed similarly for the remaining conditions. Thus, the procedure controls for differences in overall numbers of studies among material types. The $\chi^{2}$ values are calculated as the sum of squared deviations from expected values, normalized (divided) by the expected values, yielding $(1-4.24)^{2} / 4.24$ for spatial peaks reported. This value is summed over the six cells in this analysis, yielding an overall $\chi^{2}$ of 7.06. Since expected values for some cells are low (slightly less than $5)$, the results must be interpreted with caution. The $\chi^{2}$ analyses of peak counts contained many more data points. For the BA analyses, the counts shown in the bar graphs were additionally normalized by the volume of each BA, to facilitate qualitative comparisons across areas.

\section{RESULTS}

\section{Relationships Among Variables in Analysis}

Table 2 reports the numbers of peak coordinates in the literature reviewed for combinations of material types and executive operations in our analyses. As Table 2 shows, tasks involving some executive operations were more frequently imaged (and/or produced more activation peaks) with one material type. In addition, some types of executive processes tended to co-occur in tasks. This situation occurred as a by-product of the frequent study of two common paradigms, $N$-back and item recognition. $N$-back tasks require both continuous updating and memory for order but less frequently involve selective attention (since all stimuli are task relevant) and manipulation. Item recognition tasks more often involve manipulation and selective attention. In addition, $N$-back tasks were predominantly verbal, whereas item recognition tasks involved different material types more evenly.
Notably, no studies involving manipulation of object information met our inclusion criteria.

These imbalances between executive requirements and materials make it difficult to determine whether activation of a certain brain region is caused by requirements for a specific executive process, memory for a certain type of material, or some combination of the two. Because studies in which different types of materials were used differed systematically in their executive requirements (a potential cause of disagreement in findings among the studies), we chose to examine the effects of material type on the distribution of peak activation sites only for studies that involved no active executive processing. In addition, we examined the effects of executive function as a whole within each material type. There were too few studies to allow for more detailed analysis of interactions between executive functions and storage material, but we did consider cases in which confounds might influence the results when our findings were interpreted.

\section{Effects of Material Type in Simple Storage: BA Analysis}

As in previous meta-analyses (Phan et al., 2002; Smith $\&$ Jonides, 1999; Wager et al., 2003), we tested peaks within each BA for effects of material type, using $\chi^{2}$ analyses. In each analysis, we asked whether the proportion of peaks that fell within a specific BA differed as a function of whether the material to be remembered was verbal, spatial, or object in nature.

As is shown in the bar graph in Figure 1, we found evidence for dissociation between spatial and object storage in the posterior part of the brain. The $y$-axis of the graph indexes BAs, and the length of each bar along the $x$-axis indicates the proportion of total peaks reported within each BA, material type, and hemisphere, normalized by the total size of each BA. The $\chi^{2}$ analyses were

Table 2

Contingencies Between Peak Coordinate Counts for Material Types and Executive Operations

\begin{tabular}{|c|c|c|c|c|c|c|c|c|c|c|c|}
\hline \multirow[b]{2}{*}{ Condition } & \multicolumn{3}{|c|}{ Material Type } & \multicolumn{2}{|c|}{ Manipulation } & \multicolumn{2}{|c|}{$\begin{array}{l}\text { Selective } \\
\text { Attention }\end{array}$} & \multicolumn{2}{|c|}{ Updating } & \multicolumn{2}{|c|}{ Order } \\
\hline & Object & Spatial & Verbal & Yes & No & Yes & No & Continuous & Discrete & Yes & No \\
\hline \multicolumn{12}{|l|}{ Material Type } \\
\hline Object & & & & 0 & 284 & 73 & 205 & 97 & 185 & 92 & 192 \\
\hline Spatial & & & & 44 & 190 & 124 & 110 & 103 & 130 & 96 & 138 \\
\hline Verbal & & & & 54 & 441 & 179 & 340 & 263 & 256 & 330 & 182 \\
\hline \multicolumn{12}{|l|}{ Manipulation } \\
\hline Yes & 0 & 44 & 54 & & & 61 & 37 & 36 & 62 & 37 & 61 \\
\hline No & 284 & 190 & 441 & & & 307 & 643 & 468 & 485 & 522 & 434 \\
\hline \multicolumn{12}{|l|}{ Selection } \\
\hline Yes & 73 & 124 & 179 & 61 & 307 & & & 132 & 251 & 137 & 246 \\
\hline No & 205 & 110 & 340 & 37 & 643 & & & 380 & 314 & 430 & 260 \\
\hline \multicolumn{12}{|l|}{ Updating } \\
\hline Continuous & 97 & 103 & 263 & 36 & 468 & 132 & 380 & & & 407 & 105 \\
\hline Discrete & 185 & 130 & 256 & 62 & 485 & 251 & 314 & & & 160 & 404 \\
\hline \multicolumn{12}{|l|}{ Order } \\
\hline Yes & 92 & 96 & 330 & 37 & 522 & 137 & 430 & 407 & 160 & & \\
\hline No & 192 & 138 & 182 & 61 & 434 & 246 & 260 & 105 & 404 & & \\
\hline
\end{tabular}




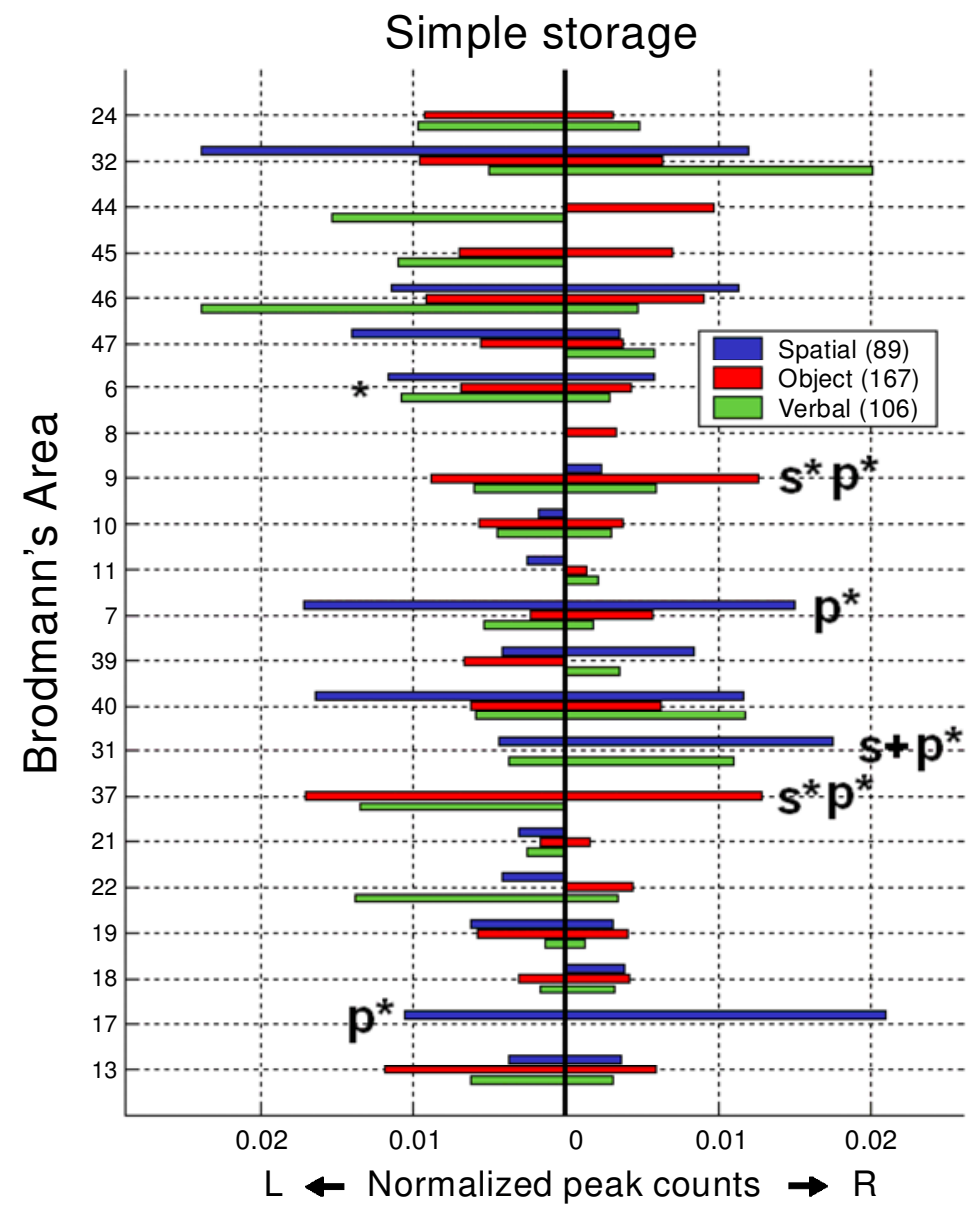

Figure 1. Comparison of material types in simple storage tasks. Brodmann's areas (BAs) are indicated on the $\boldsymbol{y}$-axis. Colored bars indicate material types, with blue, red, and green bars for spatial, object, and verbal peaks, respectively. Reported number of peak activations are shown on the $x$-axis, normalized by the total number of reported peaks for each condition and then by the area of each BA. The length of each bar corresponds to the normalized proportion of total coordinates for that material type reported within the specified $B A$. The extent of the bar to the left and right of the zero point on the $x$-axis corresponds to the proportion of peaks in the left and right hemispheres, respectively. Total numbers of counts for each condition are reported on the color key. Tasks with multidimensional stimuli (e.g., requiring selection of the relevant dimension) are included in this figure. $*$ indicates a significant lateralization overall at $p<$ $.05 . \mathrm{s} *$ indicates a difference among material types, counting studies, at $p<$ .05 . $p *$ indicates a difference among material types, counting peaks, at $p<.05$. $\mathrm{s}+$ and $\mathbf{p}+$ indicate the same effects at $p<.10$.

performed on the peak counts before size normalization. The horizontal extent of each bar thus reflects the proportion of total peak counts for one material type within the specified BA (blue bars for spatial peaks, red for object, and green for verbal), and the placement of that bar with respect to the midline represents the lateralization of the peaks.

In the posterior cortex, BA 37 showed preference for object storage $\left(\chi^{2}=6.96, p<.05\right.$, for studies; $\chi^{2}=$ $9.09, p<.05$, for peaks), and BA 7 showed preference for spatial storage $\left(\chi^{2}=15.12, p<.001\right.$, for peaks $)$, as predicted by the what versus where theory of dorsal and ventral visual streams for processing spatial and object identity information (Smith \& Jonides, 1999; Ungerleider \& Haxby, 1994).

In addition, BA 9, in the DLPFC, was selective for object storage, particularly in the right hemisphere $\left(\chi^{2}=\right.$ $7.06, p<.05$, for studies; $\chi^{2}=7.92, p<.05$, for peaks). BA 31 , in the posterior cingulate gyrus, showed a significant effect of material type as well, which reflected a complete lack of activation from object storage in this area $\left(\chi^{2}=4.04, p=.08\right.$, for studies; $\chi^{2}=8.58, p<.05$, 
for peaks). BA 17 , in the primary visual cortex, contained relatively few activation coordinates, but all the peaks reported were from spatial storage tasks $\left(\chi^{2}=\right.$ $9.28, p<.05$, for peaks). One explanation for these peaks is that there were changes in retinal stimulation due to eye movements during spatial rehearsal, but it is also possible that spatial rehearsal recruits this area more directly (see, e.g., Berman \& Colby, 2002). In addition, binomial tests on lateralization of peaks overall showed that peaks in BA 6 , in the premotor/supplementary motor cortex, were left lateralized (32 L, $15 \mathrm{R}, p<.05)$.

One result that had been expected that was not found was preferential activation in left BA 44 and 45 (Broca's area) for verbal tasks. Patients with damage to this area show difficulty in programming and initiating speech, and it is generally thought that this area implements the rehearsal of verbal information in WM (Smith, Jonides,
Marshuetz, \& Koeppe, 1998). The $\chi^{2}$ tests on material type did not show verbal selectivity for any BA. However, it appears that verbal peaks in the lateral frontal cortex, including BAs 44, 45, 46, and 6, do show left lateralization (Figure 1), and BAs 44, 45, and 46 are relatively selective for verbal information. The evidence suggests that there is indeed a verbal preference in the left lateral frontal cortex, but the peaks in this region are distributed across four BAs. Large areas of activation, which typically are produced in verbal WM studies in the left frontal lobe, may span multiple BAs, but they are usually reported with a single peak. Even if every study shows the expected effect, if spatial resolution is low or activations are large, peak coordinates may vary widely.

In BA 44 in particular, as Figure 1 shows, verbal peaks are completely left lateralized, object peaks are completely right lateralized, and no spatial storage peaks are
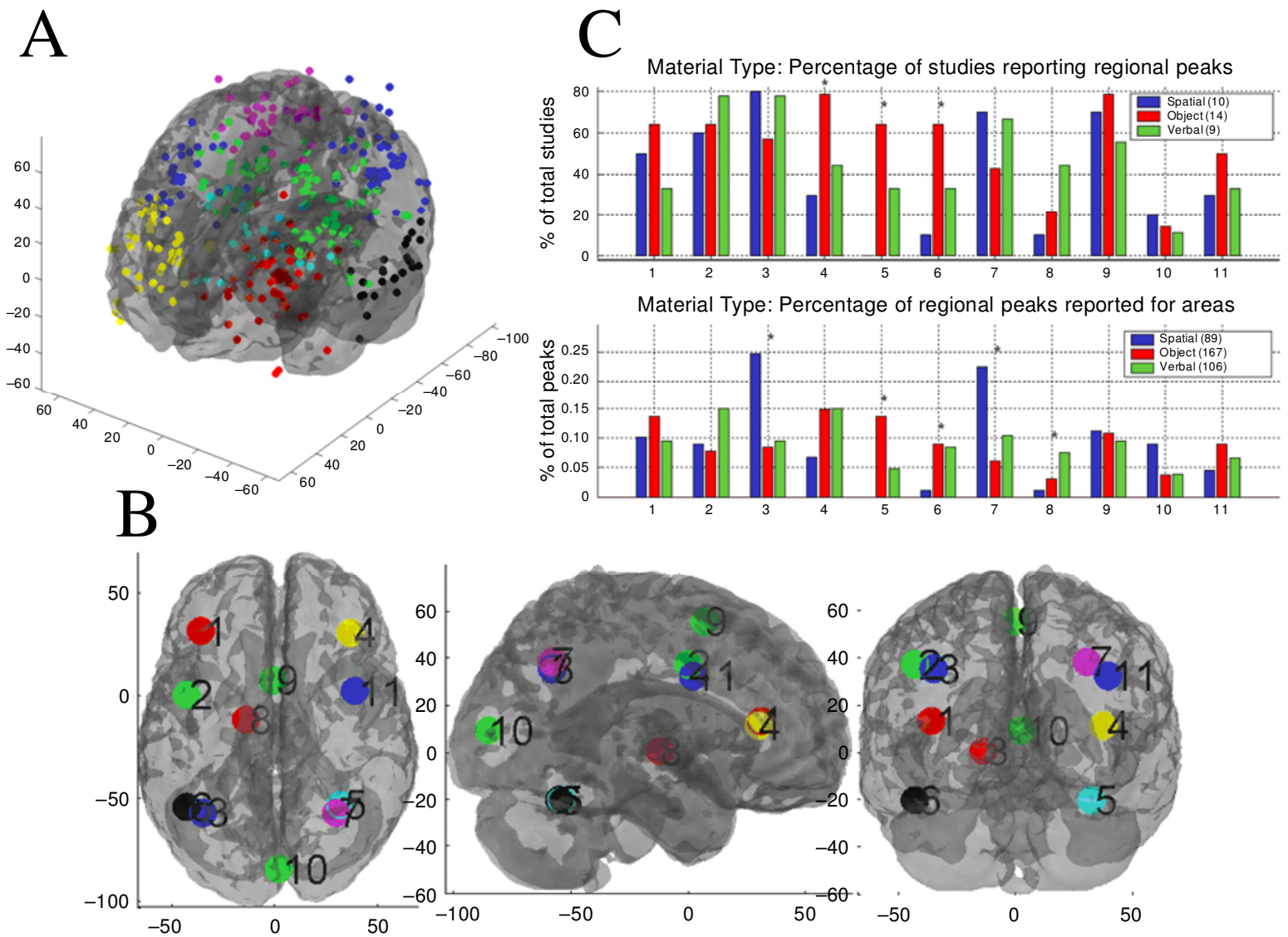

Figure 2. Results of cluster analy sis for material ty pes in simple storage. (A) Activation peaks from storage tasks (points) plotted on a transparent rendering of the MNI standard brain. Activation points are color-coded by cluster membership in the 11cluster solution; some colors are reused (e.g., two separate clusters both appear in red). Axes indicate coordinates in millimeters on the standard brain. (B) Cluster medoids, the representative peaks that best characterize the location of each cluster, numbered and shown on axial, sagittal, and coronal (from left to right) transparent views of the standard MRI brain. Color coding is by cluster, as in panel $A$. Index numbers are referred to in panel $C$ and in Table 3. (C) Frequencies of study and peak reporting for each material type in each cluster. Numbers on the $x$-axis correspond to cluster numbers in panel $B$. Colors and legend text are as in Figure 1. Chi-square analyses were performed on the frequencies of study and peak counts within each cluster, testing for differences among material types. ${ }^{*} p<.05$. $+p<.10$. 
reported. Although this fits the expected pattern, there are too few reported peaks in this relatively small area of the cortex for the effect to reach significance.

\section{Effects of Material Type in Simple Storage: Cluster Analysis}

The results of the cluster analysis are summarized in Figure 2. Figure 2A shows the distribution of peaks throughout the brain, color-coded according to their cluster assignment (some colors are reused). Figure 2B shows the medoids (representative peaks) for each cluster on axial, sagittal, and coronal views of a transparent canonical brain, numbered for reference and color-coded as in Figure 2A. Figure 2C shows the distribution of peaks by material type in each cluster. Numbers on the $x$-axis in Figure $2 \mathrm{C}$ correspond to the cluster numbers in Figure $2 \mathrm{~B}$, and results from counting studies and peaks are shown in the top and bottom panels of Figure 2C. In addition, cluster locations and BA composition are shown in Table 3.

As Figure 2 shows, the distinction between the dorsal (spatial) and the ventral (object) processing streams was clearly shown in the $\chi^{2}$ analysis on clusters from passive storage tasks. Clusters 3 and 7 in the 11-cluster solution were located in the left and the right parietal cortex, respectively (Figure 2B, center panel), and showed a clear preference for spatial memory when peaks are counted (Figure 2C, Table 3 ), although these regions were also activated in a high proportion of verbal studies [Cluster 3 (L), $\chi^{2}=15.42, p<.001$, for peaks; Cluster $7(\mathrm{R}), \chi^{2}=$
$15.84, p<.001$, for peaks]. As in the Brodmann analysis, the right frontal cortex (Cluster 4) was specific for object WM $\left(\chi^{2}=6.06, p<.05\right.$, for studies $)$, as were the right and the left inferior temporal cortices [Cluster 6 (L), $\chi^{2}=7.39, p<.05$, for studies, and $\chi^{2}=6.16, p<$ .05 , for peaks; Cluster $5(\mathrm{R}), \chi^{2}=10.47, p<.01$, for studies, and $\chi^{2}=17.34, p<.001$, for peaks]. Thus, the classic double dissociation between spatial storage in the superior parietal cortex and object storage in the inferior parietal cortex is evident in this data set.

Surprisingly, clusters in the left frontal cortex (Cluster 2, most of whose peaks were in BAs 6 and 9, but whose center is near BA 44 on the inferior frontal gyrus) did not show a significant verbal WM specificity $\left(\chi^{2}=3.97\right.$, $p=.14$, counting peaks), although it approached significance. As in the BA analysis, it is possible that verbal peaks are spread out over several clusters. In support of this idea, Cluster 8, whose peaks were mostly in the left thalamus and basal ganglia, also showed significant preference for verbal storage ( $\chi^{2}=6.01, p<.05$, for peaks). It is possible that the left striatum (caudate and putamen), which is broadly implicated in motor control and contains cells that code for serial order in movement (Aldridge \& Berridge, 1998), is an important structure in the mediation of subvocal rehearsal.

\section{Analyses of Executive Processing: BA Analysis}

Analysis of executive processing requirements showed significantly greater activation frequency for continuous updating, temporal order memory, and manipulation in

Table 3

Cluster Analysis Results for Passive Storage

\begin{tabular}{|c|c|c|c|c|c|c|c|c|c|}
\hline \multirow[b]{2}{*}{ Index } & \multirow{2}{*}{$\begin{array}{l}\text { No. } \\
\text { Peaks }\end{array}$} & \multicolumn{3}{|c|}{ Medoid } & \multicolumn{3}{|c|}{ Geometric Center } & \multirow[b]{2}{*}{ ASI } & \multirow[b]{2}{*}{ Regions Spanned } \\
\hline & & $x$ & $y$ & $z$ & $x$ & $y$ & $z$ & & \\
\hline 1 & 42 & -36 & 31 & 13 & -33 & 32 & 12 & 0.36 & $\begin{array}{l}\text { BA } 10(19 \%), \text { BA } 46(19 \%), \text { BA } 9(14 \%), \text { BA } 13(12 \%) \text {, } \\
\text { BA } 47(12 \%) \text {, Unknown }(12 \%) \text {, Put }(7 \%)\end{array}$ \\
\hline 2 & 37 & -43 & 0 & 37 & -43 & 2 & 37 & 0.41 & BA $6(57 \%)$, BA $9(22 \%)$ \\
\hline 3 & 46 & -35 & -58 & 35 & -31 & -61 & 38 & 0.39 & $\begin{array}{l}\text { BA } 7(30 \%), \text { BA } 40(28 \%), \text { BA } 19(15 \%), \text { BA } 39(13 \%), \\
\text { BA } 31(4 \%) \text {, Unknown }(4 \%)\end{array}$ \\
\hline 4 & 47 & 37 & 30 & 11 & 33 & 31 & 12 & 0.35 & $\begin{array}{l}\text { BA } 9(23 \%), \text { Unknown }(21 \%), \text { BA } 10(13 \%), \text { BA } 46(11 \%), \\
\text { BA } 47(9 \%), \text { BA } 13(6 \%), \text { BA } 11(4 \%), \text { Put }(4 \%)\end{array}$ \\
\hline 5 & 28 & 32 & -54 & -21 & 32 & -49 & -20 & 0.39 & $\begin{array}{l}\text { Cerebellum (39\%), BA } 37(29 \%), \text { BA } 19(14 \%), \\
\text { Amy }(4 \%), \text { BA } 20(4 \%), \text { BA } 21(4 \%), \text { BA } 22(4 \%), \text { BA } 36(4 \%)\end{array}$ \\
\hline 6 & 25 & -43 & -55 & -21 & -44 & -52 & -15 & 0.40 & $\begin{array}{l}\text { BA } 37(32 \%), \text { BA } 19(20 \%), \text { BA } 22(16 \%), \\
\text { Cerebellum }(16 \%) \text {, BA } 21(12 \%), \text { BA } 20(4 \%)\end{array}$ \\
\hline 7 & 41 & 30 & -58 & 38 & 28 & -58 & 40 & 0.43 & $\begin{array}{l}\text { BA } 7(41 \%), \text { BA } 40(34 \%), \text { BA } 39(10 \%), \text { BA } 31(7 \%), \\
\text { BA } 19(5 \%)\end{array}$ \\
\hline 8 & 14 & -14 & -12 & 0 & -14 & -11 & 3 & 0.26 & $\begin{array}{l}\text { Tha (36\%), Glo (14\%), BA } 13(7 \%) \text {, BA } 21(7 \%) \text {, BA } 23(7 \%) \text {, } \\
\text { BA } 24(7 \%) \text {, BA } 34(7 \%) \text {, Cau (7\%), Put }(7 \%)\end{array}$ \\
\hline 9 & 38 & -1 & 7 & 55 & -1 & 5 & 52 & 0.36 & BA $6(63 \%)$, BA $32(21 \%)$, BA $24(5 \%)$, BA $31(5 \%)$, BA $8(5 \%)$ \\
\hline 10 & 18 & 2 & -85 & 9 & 4 & -81 & 4 & 0.46 & $\begin{array}{l}\text { BA } 18(44 \%), \text { BA } 17(17 \%), \text { BA } 19(11 \%), \text { BA } 30(11 \%), \\
\text { BA } 31(11 \%) \text {, BA } 23(6 \%)\end{array}$ \\
\hline 11 & 26 & 39 & 2 & 32 & 38 & -2 & 33 & 0.28 & $\begin{array}{l}\text { BA } 6(42 \%), \text { BA } 9(27 \%), \text { BA } 13(8 \%), \text { Cau }(8 \%) \\
\text { BA } 2(4 \%), \text { BA } 22(4 \%), \text { BA } 8(4 \%), \text { Put }(4 \%)\end{array}$ \\
\hline
\end{tabular}

Note-Each reported peak for passive storage studies was classified as belonging to one of 11 clusters based on reported peak coordinates and was numbered for reference as in Figure 2. For each cluster, we report the medoid (see the Method section), the geometric center of the cluster in MNI coordinates, and the average silhouette index (ASI; a measure of clustering quality). The anatomical locations of peaks in the cluster are reported in terms of percentage of peaks falling within particular Brodmann areas (for the cortex) and regions (for subcortical areas), for all regions that contain at least $5 \%$ of the total number of peaks in the cluster. Put, putamen; Amy, amygdala; Tha, thalamus; Glo, globus pallidus; Cau, caudate. Unknown regions include white matter, CSF space, and small structures not labeled in our broad classification (e.g., nucleus accumbens, claustrum, etc.). 
several frontal and parietal regions. The bar graph in Figure 3 provides a summary of the relative frequency of activation in each executive function, as compared with storage-only tasks. The height of each bar (green for continuous updating, blue for temporal order, and yellow for manipulation) shows the frequency of activation for studies (top panel) and peaks (bottom panel) for each executive process minus the frequency of activation for storage-only tasks. The frequency for a condition (e.g., updating) is calculated as the percentage of total peaks for a condition that falls within the selected region. Thus, a positive value in Figure 3 indicates greater frequency in executive function with that BA (controlling for the overall number of studies/peaks), and negative values indicate greater frequency in storage-only tasks. ${ }^{1}$

Figure 3 shows that BA 7 is the most frequently activated region in executive processing. It is significant for updating $\left(\chi^{2}=6.27\right.$ for studies, 6.58 for peaks, $\left.p<.05\right)$, $\operatorname{order}\left(\chi^{2}=7.01\right.$ for studies, 3.97 for peaks, $\left.p<.05\right)$, and manipulation $\left(\chi^{2}=3.55, p=.06\right.$, for studies; $\chi^{2}=$ $5.72, p<.05$, for peaks). Figure 4 provides information about the lateralization of executive functions, using the same kind of bar graph as that employed in our previous analysis of material type (Figure 1). Figure 4 shows that the distribution of peaks in BA 7 is roughly symmetrical across hemispheres. BAs 6,8 , and 9 are significant for updating $\left(\chi^{2}\right.$ for BAs $6,8,9=0.22,5.40^{*}$, and 2.65 for studies and $4.84 *, 4.64 *$, and $4.00 *$ for peaks; $*$ denotes $p<.05)$ and order $\left(\chi^{2}\right.$ for BAs $6,8,9=0.37,2.82^{+}$, and $4.37^{*}$ for studies and $4.11^{*}, 2.31$, and $5.23^{*}$ for peaks; $*$ denotes $p<.05,{ }^{+}$denotes $p<.10$ ). In BA 6 , additional activations due to continuous updating $\left(\chi^{2}=4.88\right.$, $p<.05$, for peaks) and order memory $\left(\chi^{2}=4.69, p<\right.$ .05 , for peaks) are lateralized to the right hemisphere, as is shown by significant laterality $\times$ executive demand interactions (Figure 4). BA 47, in the inferior part of the lateral frontal cortex, showed more frequent activation for manipulation, as compared with storage in the right hemisphere (laterality $\times$ manipulation demand, $\chi^{2}=4.15$, $p<.05$, for peaks). BA 46 , adjacent to BA 47 , showed the same pattern, although the results were not significant.

BAs 44 and 45 showed a qualitatively different pattern. The only executive function that showed a trend toward more frequent activation, as compared with storage tasks, was temporal order memory (BA $44, \chi^{2}=3.42$, $p=.06$, for studies; BA 45 , n.s.). The small size of these areas results in relatively few peak coordinates and low statistical power.

A fourth type of pattern among executive functions was found in BA 10, in the anterior frontal cortex. BA 10 showed a significant effect of manipulation $\left(\chi^{2}=4.84\right.$, $p<.05$, for peaks) and a trend toward selectivity for continuous updating $\left(\chi^{2}=3.30, p=.07\right.$, for peaks; Figure 3 ). Both effects are likely to be localized to the right hemisphere, although $\chi^{2}$ values were not significant $\left(\chi^{2}=2.60, p=.11\right.$, for manipulation peaks; $\chi^{2}=2.4$, $p=.12$, for updating peaks; Figure 4 ).

\section{Analyses of Executive Processing: Cluster Analysis}

Figure 5 shows a summary of the cluster analysis results, in the same format as the previous cluster analysis of storage material. Figure 5A shows points for the 15cluster solution, which was chosen because it maximized clustering strength while providing anatomical specificity consistent with the size and variability of the data set. Figure 5B and Table 4 show the cluster medoids, and Figure 5C shows the specialization for each executive function within each cluster.

Four clusters showed the pattern observed in the previous analysis of significant specialization for both continuous updating and temporal order memory. Those are the right DLPFC (Cluster 4, primarily in BAs 9 and 10; $\chi^{2}=3.57$ for updating, $\chi^{2}=3.27$ for order, counting studies, both $p$ s $<.10$ ), the right medial and lateral parietal cortex (Cluster 7, BAs 7 and $40 ; \chi^{2}=7.01$ for updating, and $\chi^{2}=5.96$ for order, counting studies; both $p$ s $<.05$ ), and the bilateral SFS (Clusters 12 and 15, in right and left BA $6 ; \chi^{2}$ for $\mathrm{L} / \mathrm{R}=14.46 / 7.46$ for updating, counting studies, and $\chi^{2}=11.69 / 8.17$, counting peaks, all $p \mathrm{~s}<.01 ; \chi^{2}=10.34 / 6.89$ for order, counting studies, and $\chi^{2}=9.36 / 7.13$, counting peaks, all $p$ s $<$ $.05)$. Centers and composition of these clusters are reported in Table 4. Two clusters, in the precuneus (Cluster 9) and the cuneus (Cluster 11), showed trends toward specialization for manipulation, when one counted peaks $\left(\chi^{2}=2.77\right.$ for the precuneus and 2.77 for the cuneus, both $p$ s $<.10$, for peaks). This finding suggests that peaks for manipulation are more medially distributed than those for continuous updating and order memory in the parietal cortex. The expected specialization for manipulation in the right frontal cortex (Cluster 4), which would parallel the findings for BAs 47 and 10 in the BA analysis, did not reach significance.

\section{Interactions Between Executive Demand and Material Type}

One important point that the previous analyses do not address is the possibility that brain regions are selectively activated by a combination of storage material and executive demand. In particular, one prior hypothesis about such an interaction is that verbal storage tasks should produce left-lateralized frontal activation and executive demand in verbal storage should additionally recruit the right frontal cortex.

Figure 6 shows the frequency and lateralization of peaks for executive demand, as compared with simple storage, for each material type (spatial, object, and verbal). The figure shows that simple storage peaks are indeed left lateralized within BAs 44, 45, and 46, although this effect is not significant for any single BA, and that addition of executive demand produces a significant increase in right-lateralized peaks within BAs 45 and 46 , as shown by a significant executive demand $\times$ hemisphere interaction $\left(\chi^{2}=3.43, p=.06\right.$, for peaks in BA $45 ; \chi^{2}=3.43, p=$ 

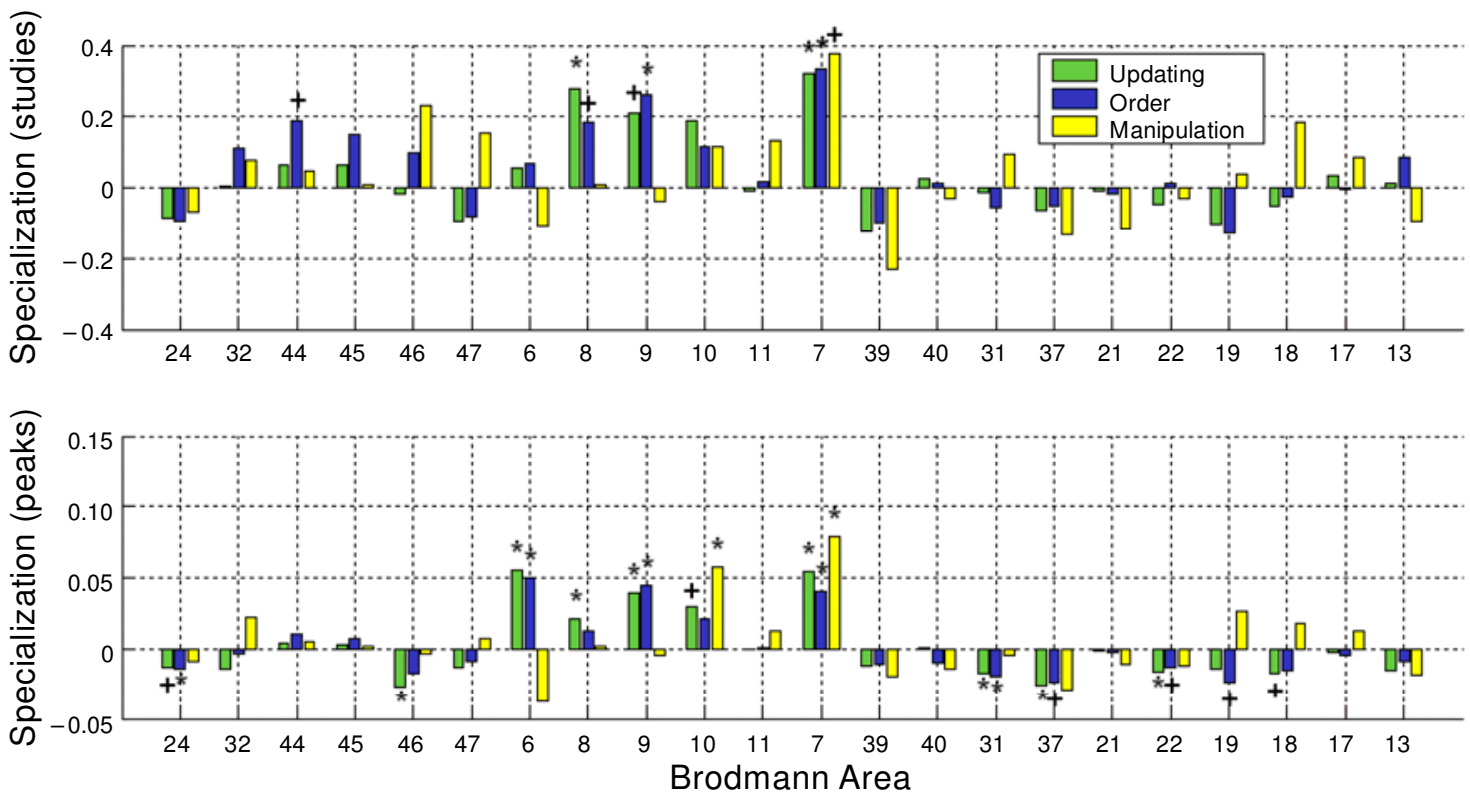

Figure 3. Specialization index for each of the three types of executive demand in comparison with simple storage. Tasks requiring selection are included in the storage category. The $x$-axis indicates Brodmann's areas, and the $y$-axis shows specialization, computed as the proportion of studies showing activation (top panel) or activation peaks (bottom panel) for each executive demand, in comparison with the proportion in storage only. The zero point on the $y$-axis indicates equal proportions in storage + executive and storage-only tasks. Green, blue, and yellow indicate the three executive functionscontinu ous updating, temporal order memory, and manipulation of information in working memory, in that order. * $p<$ $.05 .+p<.10$.
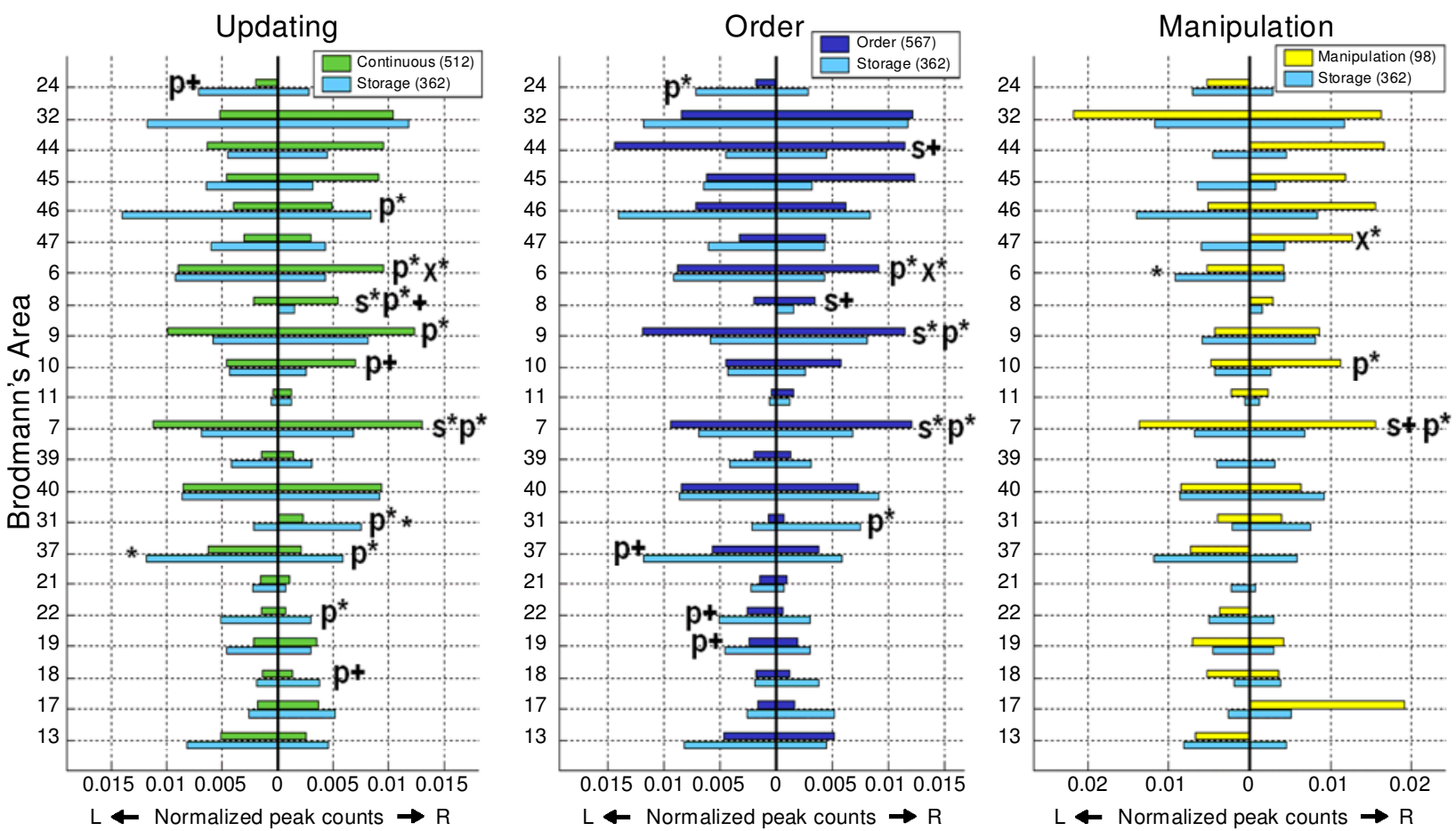

Figure 4. Frequencies for each executive function in comparison with storage-only tasks for each Brodmann's area. Labels and axes are as in Figure 1. Tasks requiring selection are included in the storage category. * indicates a significant lateralization overall at $p<$ $.05 . \mathrm{s}^{*}$ indicates a difference among material types, counting studies, at $p<.05$. $\mathrm{p}^{*}$ indicates a difference among material types, counting peaks, at $p<.05 . x^{*}$ indicates a significant condition (executive vs. storage) $\times$ hemisphere interaction, counting peaks, at $p<.05$. $\mathrm{s}+, \mathrm{p}+$, and $\mathrm{x}+$ indicate the same effects at $p<.10$. 


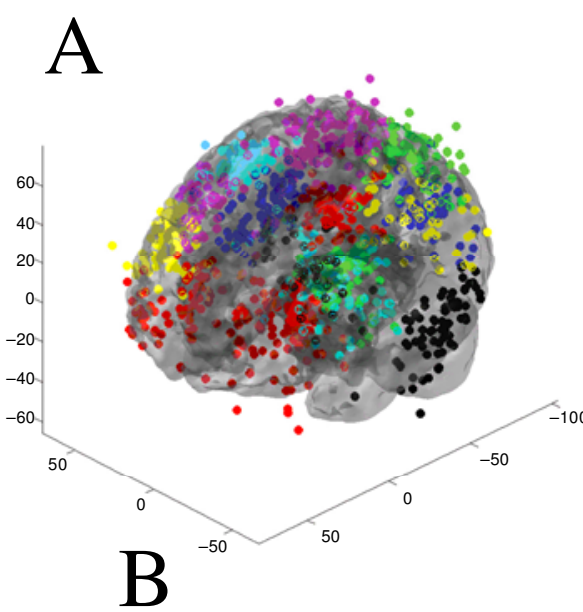

$\mathrm{C}$
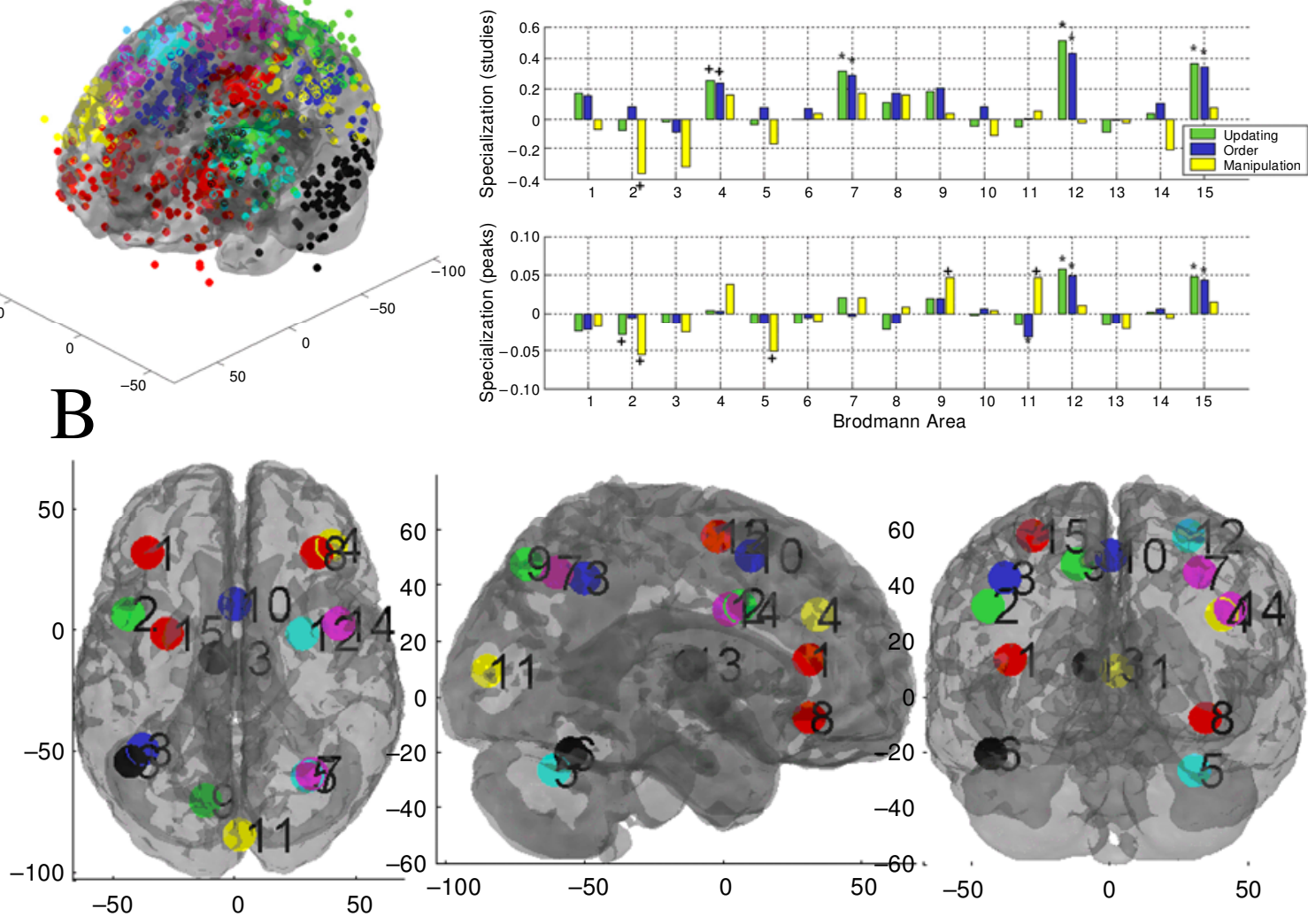

Figure 5. Cluster analysis of all working memory activation peaks, testing for effects of particular executive functions, in comparison with storage-only tasks, in each cluster. (A) All reported activation peaks, classified and color-coded into 15 clusters based on goodness-of-clustering measures, comparable to those in Figure $2 \mathrm{~A}$. Some colors are reused. (B) Medoids, numbered according to cluster index, superimposed on axial, sagittal, and coronal transparent brains, as in Figure 2B. (C) Specialization within each cluster for each executive function, as in Figure 3. Numbers on the $x$-axis indicate cluster identity and correspond to numbers in panel $B$ and in Table 3. *p $<.05 .+p<.10$.

.06 , for peaks in BA $45 ; \chi^{2}=4.10, p<.05$, for peaks in BA 46; Figure 6 , right panel). This pattern of activations was also found for BA $6\left(\chi^{2}=4.10, p<.05\right.$, for peaks $)$.

In spatial tasks, there was a significant executive demand $\times$ hemisphere interaction in BA 32 , so that executive tasks produced more right-hemisphere peaks $\left(\chi^{2}=\right.$ $5.24, p<.05$, for peaks) and more frequent activation with executive demand in BAs 9 and 10 (in BA 9, $\chi^{2}=$ 7.07, $p<.01$, for studies, and $\chi^{2}=5.51, p<.05$, for peaks; in BA $10, \chi^{2}=4.70, p<.05$, for studies, and $\chi^{2}=4.89, p<.05$, for peaks), with a trend toward right lateralization in BA $10\left(\chi^{2}=2.94, p<.10\right.$, for peaks $)$.

In contrast to regions that showed specific executive process $\times$ material type interactions, BA 7, in the superior parietal cortex, showed greater involvement with executive demand in all three material types $\left(\chi^{2}=3.67, p=\right.$ .06 , counting spatial studies; $\chi^{2}=6.13, p<.05$, counting object studies; $\chi^{2}=3.87, p<.05$, counting verbal peaks).

\section{Effects of Selective Attention}

BA analysis. Selective attention involves storing one attribute of a multidimensional stimulus in WM while ignoring irrelevant attributes. We compared peaks from storage tasks that required selective attention (2-D stimuli), but no other executive process, with those from 1-D storage-only tasks. Our results show that selective attention produced significantly more frequent activation in BA 32 , in the medial PFC ( $\chi^{2}=4.52, p<.05$, for peaks).

Cluster analysis. In the cluster analysis, selective attention, as compared with simple storage, produced more frequent activations in Cluster 5 (see Figure 5B for cluster locations), in the right inferior temporal cortex $\left(\chi^{2}=3.94, p<.05\right.$, for peaks), with a trend toward significance in Cluster 9, in the medial PFC $\left(\chi^{2}=3.62\right.$, $p=.06$, for peaks).

\section{DISCUSSION}

\section{Effects of Storage Material}

In both BA and cluster analyses, we found the expected pattern of dissociations between spatial and object (nonspatial visual) storage in the posterior cortex. Spatial storage tasks most frequently activated the superior parietal cortex, and object storage most frequently activated the inferior temporal cortex. However, we found that even nonspatial storage tasks were likely to produce peak 
Table 4

Cluster Analysis Results for Executive Functions

\begin{tabular}{|c|c|c|c|c|c|c|c|c|c|}
\hline \multirow[b]{2}{*}{ Index } & \multirow{2}{*}{$\begin{array}{l}\text { No. } \\
\text { Peaks }\end{array}$} & \multicolumn{3}{|c|}{ Medoid } & \multicolumn{3}{|c|}{ Geometric Center } & \multirow[b]{2}{*}{ ASI } & \multirow[b]{2}{*}{ Regions Spanned (Percentage of Peaks in Each Region) } \\
\hline & & $x$ & $y$ & $z$ & $x$ & $y$ & $z$ & & \\
\hline 1 & 107 & -36 & 31 & 13 & -32 & 34 & 11 & 0.27 & $\begin{array}{l}\text { BA } 10(25 \%) \text {, BA } 9(13 \%) \text {, BA } 46(12 \%) \text {, Unknown }(11 \%) \text {, } \\
\text { BA } 47(10 \%) \text {, BA } 13(9 \%) \text {, BA } 11(6 \%) \text {, Put }(6 \%)\end{array}$ \\
\hline 2 & 79 & -44 & 6 & 32 & -45 & 7 & 32 & 0.38 & $\begin{array}{l}\text { BA } 9(41 \%), \text { BA } 6(32 \%), \text { BA } 8(6 \%), \text { BA } 44(5 \%) \\
\text { BA } 46(5 \%)\end{array}$ \\
\hline 3 & 72 & -38 & -50 & 42 & -37 & -51 & 41 & 0.39 & BA $40(57 \%)$, BA $39(14 \%)$, BA $7(11 \%)$ \\
\hline 4 & 86 & 40 & 34 & 29 & 36 & 36 & 28 & 0.40 & $\begin{array}{l}\text { BA } 9(44 \%) \text {, BA } 10(26 \%) \text {, BA } 46(13 \%) \text {, Unknown }(8 \%) \text {, } \\
\text { BA } 8(6 \%)\end{array}$ \\
\hline 5 & 70 & 30 & -61 & -27 & 29 & -56 & -26 & 0.36 & Cerebellum (50\%), BA 37 (23\%), BA $19(14 \%)$ \\
\hline 6 & 71 & -43 & -55 & -21 & -42 & -55 & -20 & 0.42 & $\begin{array}{l}\text { BA } 37(30 \%), \text { Cerebellum }(24 \%), \text { BA } 19(14 \%), \\
\text { BA } 21(10 \%), \text { BA } 22(10 \%), \text { BA } 20(7 \%), \text { BA } 18(6 \%)\end{array}$ \\
\hline 7 & 114 & 32 & -60 & 44 & 31 & -59 & 43 & 0.45 & BA $7(47 \%)$, BA $40(32 \%)$, BA $19(5 \%)$ \\
\hline 8 & 61 & 34 & 31 & -8 & 34 & 31 & -4 & 0.22 & $\begin{array}{l}\text { BA } 47(28 \%) \text {, BA } 10(16 \%) \text {, BA } 11(15 \%) \text {, BA } 13(15 \%) \text {, } \\
\text { Unknown (10\%), Put }(7 \%)\end{array}$ \\
\hline 9 & 72 & -12 & -71 & 47 & -12 & -70 & 46 & 0.30 & BA $7(85 \%)$, BA $19(8 \%)$, BA $31(6 \%)$ \\
\hline 10 & 84 & 0 & 10 & 50 & 0 & 11 & 49 & 0.39 & BA $6(51 \%)$, BA $32(31 \%)$, BA $8(11 \%)$ \\
\hline 11 & 46 & 2 & -85 & 9 & 2 & -84 & 7 & 0.25 & $\begin{array}{l}\text { BA } 18(37 \%), \text { BA } 19(30 \%), \text { BA } 17(20 \%), \text { BA } 30(7 \%), \\
\text { BA } 31(4 \%)\end{array}$ \\
\hline 12 & 65 & 28 & -2 & 57 & 27 & 0 & 56 & 0.43 & BA $6(89 \%)$, BA $8(6 \%)$ \\
\hline 13 & 37 & -8 & -12 & 11 & -5 & -12 & 9 & 0.40 & $\begin{array}{l}\text { Tha (43\%), Cau (16\%), Put (16\%), BA } 13(5 \%) \text {, BA } 23(5 \%) \text {, } \\
\text { Glo (5\%) }\end{array}$ \\
\hline 14 & 52 & 43 & 2 & 31 & 45 & 1 & 29 & 0.25 & BA $6(37 \%)$, BA $9(31 \%)$, BA $44(8 \%)$, BA $13(6 \%)$ \\
\hline 15 & 70 & -28 & -2 & 57 & -28 & -4 & 56 & 0.42 & BA $6(86 \%)$, BA $4(9 \%)$ \\
\hline
\end{tabular}

Note-Each reported peak across all studies was classified as belonging to one of 15 clusters based on reported peak coordinates and was numbered for reference as in Figure 5. ASI, average silhouette index; Tha, thalamus; Cau, caudate; Put, putamen; Glo, globus pallidus.

activations in the parietal cortex; spatial tasks simply produced more peaks per study. In contrast, inferior temporal activations were relatively specific to object WM. Below, we review several specific hypotheses.
Hemispheric lateralization of verbal and spatial material in the PFC. We found some support for left lateralization of verbal WM across three BAs $(44,45$, and 46) in the inferior frontal cortex, located in the vicin-
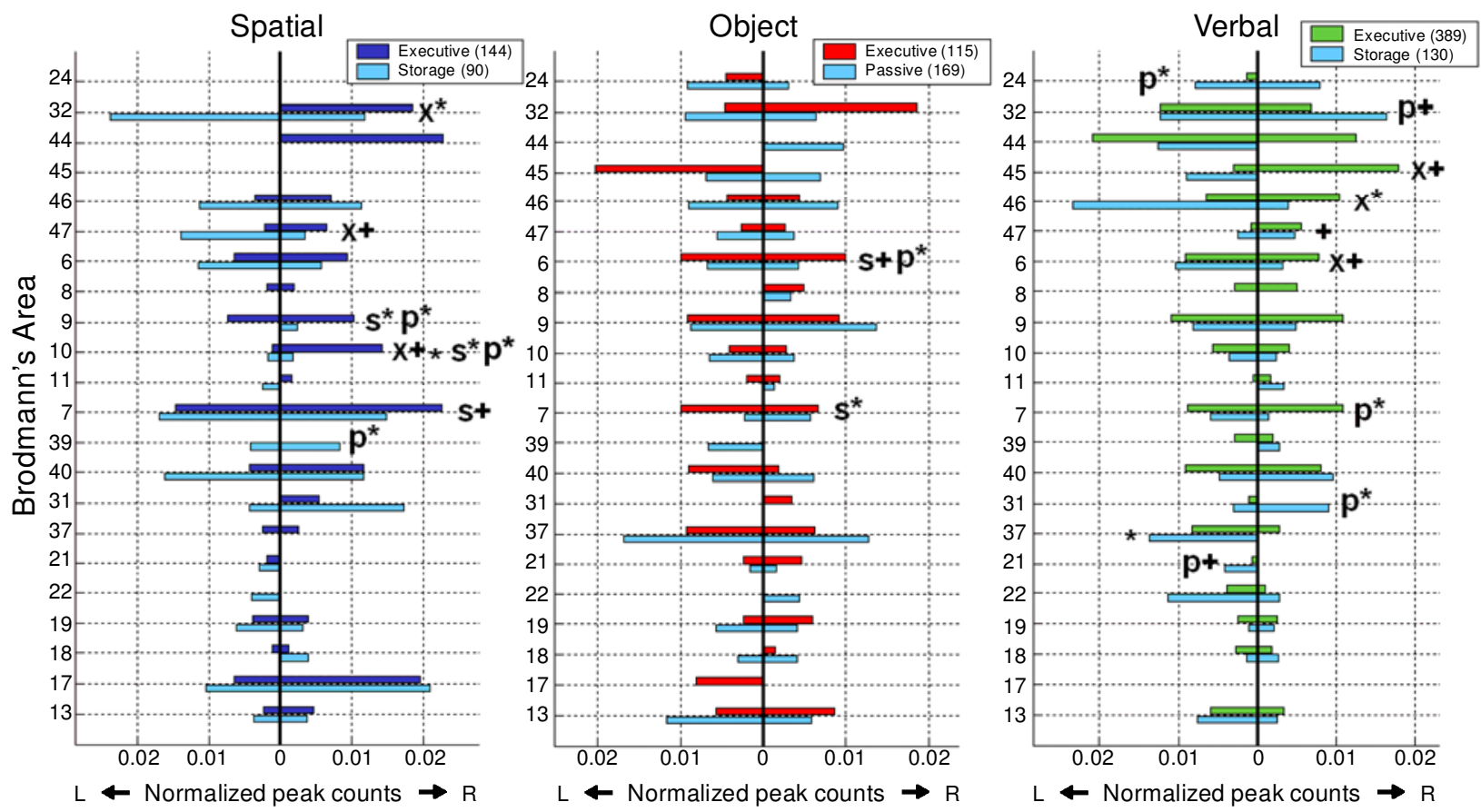

Figure 6. Comparison of executive function (collapsing across executive subtypes) with storage-only tasks within each material type. Axes and text labels are interpreted as in Figure 1 and Figure 4. 
ity of Broca's area, as well as in BA 6. Hemisphere $\times$ executive demand interactions for verbal WM indicated that left lateralization was found only for simple storage tasks. This effect is much weaker than that suggested by individual studies, which may be due to the high spatial variability of peaks across studies and the small sizes of relevant BAs. In addition, the cluster analysis revealed that some verbal WM left lateralization may occur in the insula and subcortical regions.

Chein and Fiez (2001), in the only verbal storage study included in the meta-analysis that isolated delay activity in an event-related design, found two separate foci selective for verbal WM maintenance in the left inferior PFC, but they also found such areas in the right inferior PFC. Thus, the meta-analysis results appear to be representative of individual studies that isolate maintenance activity in verbal WM.

Dorsal/ventral separation of spatial and object WM. A prevalent hypothesis in the literature is that the DLPFC, or more precisely, the SFS, is specialized for spatial WM, whereas the ventrolateral PFC is relatively specialized for object WM. This notion has been supported by a number of animal (Levy \& Goldman-Rakic, 1999) and human (Courtney et al., 1998) studies. However, our findings do not support the hypothesis that WM representations in the PFC are organized according to material type. We found no evidence for a spatial-object dissociation across studies within the dorsal and the ventral lateral PFC in either BA or cluster analyses; in fact, spatial storage tasks were somewhat more likely to produce peak activations in BAs 46 and 47 , and object WM tasks were significantly more likely to produce peaks in right dorsolateral BA 9 (and the right anterior/dorsolateral $\mathrm{PFC}$ in the cluster analysis). This finding is contrary to current models of material-specific organization (Funahashi, Bruce, \& Goldman-Rakic, 1989; Funahashi et al., 1993; Smith, Jonides, \& Koeppe, 1996; Smith et al., 1995). Our results agree more closely with those of Owen et al. (1999; Owen et al., 1998), who proposed frontal specialization according to requirements for particular executive processes, with the DLPFC more active in executive processing and the ventral frontal cortex responsible for storage-related processes. This view also agrees with other meta-analytic reviews (Owen, 2000).

In contrast, as has been described above, what emerged clearly from our analyses was a double dissociation between spatial maintenance in the parietal cortex (dorsal stream) and object maintenance in the temporal cortex (ventral stream), as would be expected from animal studies on visual processing (e.g., Ungerleider \& Haxby, 1994) and previous meta-analyses (Smith \& Jonides, 1999). Thus, dissociations in perceptual-processing streams are mirrored in the WM system, even when control tasks are matched on perceptual and motor requirements, highlighting the overlap between the posterior brain areas involved in perception and memory.

The failure to find a dorsal-ventral distinction among material types in the frontal cortex does not demonstrate that no material type effects exist. For example, we found greater frequency of object storage peaks in the right lateral frontal cortex, particularly in BA 9. One reasonable intermediate position is that the processes involved in the maintenance of information differ depending on storage material. Object storage may involve serial selective attention to object features in WM, which could explain specialization both for object storage and for continuous updating and order tasks in the DLPFC. Spatial rehearsal may involve rehearsal of intended movements to different locations, producing the spatial memory effects apparent in the superior parietal cortex by virtue of that region's role in spatial attention and coordinate transformations (Colby \& Goldberg, 1999). Verbal rehearsal likely involves subvocal repetition of words. The left ventral PFC showed some evidence for verbal specificity; among executive processes, order memory produced the greatest effects in this region, suggesting a possible relationship between requirements for verbal storage and stimulus ordering.

Hemispheric lateralization of spatial and object WM. Some individual studies (Smith et al., 1995) and at least one meta-analytic review (D'Esposito et al., 1998) have found evidence for left lateralization of object WM and right lateralization of spatial WM. However, views on this issue derived from both single-study and meta-analy tic perspectives have been mixed (Courtney et al., 1998). We found some evidence that object storage is more likely than storage of other materials to produce activation in the right frontal cortex, in contradiction to the lateralization hypothesis. However, it appears to be roughly consistent with the proposal of Courtney et al. (1998) that imagebased rehearsal strategies preferentially involve the right frontal cortex. We did not find hemispheric asymmetries for spatial material, except that the frontal cortex (BAs 47, 10, and 32; Figure 6) showed greater right lateralization when executive functions were demanded in spatial tasks. Thus, findings on lateralization in spatial WM may depend on the level of executive demand or task difficulty. The hypothesized hemispheric lateralization may be more likely to occur if spatial tasks are more difficult than their verbal counterparts.

Additional findings. In contrast with findings of object preference in the right frontal cortex, the precuneus (BA 31) contains numerous peaks for spatial and verbal storage, but no reported activations for object storage tasks. Also, only spatial storage tasks produced activations in the primary visual cortex. ${ }^{2}$ This may be attributed to a spatial rehearsal strategy that depends on eye movements; however, corresponding activations in the frontal eye fields are not more frequent for spatial storage than for other kinds of storage, suggesting that this account is not enough to explain the activation in the visual cortex (see also Berman \& Colby, 2002).

\section{Effects of Executive Processing}

As was expected, effects of executive processes were found primarily in the frontal and parietal cortices, including the anterior prefrontal, the DLPFC and ventral lateral prefrontal, the bilateral premotor (centered in the SFS), and the lateral and medial superior parietal cor- 
tices. Other areas also showed activations in executive function tasks, but only in the aforementioned regions did we find that the presence of executive demand significantly increased the probability of activation.

Manipulation versus storage. Several groups (e.g., D'Esposito et al., 1998; Owen, 1997, 2000) have proposed that storage tasks, without executive processing requirements, activate the ventral PFC, whereas manipulation of information (in a general sense that includes continuous updating) recruits the mid-DLPFC. However, other studies have shown evidence for executive effectsspecifically, inhibition - in the ventral PFC (D'Esposito, Postle, Jonides, \& Smith, 1999; Jonides, Smith, Marshuetz, Koeppe, \& Reuter-Lorenz, 1998). Our results generally support the dorsal-executive hypothesis: The bilateral SFS and the DLPFC showed the greatest specialization among frontal regions for continuous updating and temporal order memory, in both the BA and the cluster analyses. However, not all executive functions showed the same effects. We found that manipulation-which, in our classification, primarily involved operations on stimuli while maintaining items in $\mathrm{WM}$ - produced the greatest increases in right BAs 46 and 47, in the ventral $\mathrm{PFC}$, and in BA 10 (anterior PFC) primarily in the right hemisphere.

How do we resolve this apparent discrepancy between our meta-analytic results and the literature on manipulation? Part of the discrepancy is definitional. Such tasks as the $N$-back task and self-ordered tasks are classified as manipulation tasks in the literature (e.g., Owen, Evans, \& Petrides, 1996). We classify these tasks as involving continuous updating and order memory, but not manipulation. Our meta-analysis shows that updating and order requirements lead to more frequent superior frontal, but not inferior frontal, activation. We reserved the term manipulation for other kinds of operations, such as tasks that require concurrent memory maintenance and arithmetic operations. These tasks all involve transforming the identity or characteristics of stimuli in WM, as with arithmetic operations, and are likely to involve shifting attention and inhibition of irrelevant stimulus dimensions. Manipulation tasks produce greater inferior frontal activation, and they may constitute a separate kind of executive process.

Notably, in one of the few cases of disagreement between $\chi^{2}$ and cluster analyses, the manipulation results in BAs 10 and 47 do not appear in the cluster analysis. One explanation is that the cluster analysis produced a coarser segregation into regions that cut across BA boundaries and effects in these relatively small BAs were masked. Be that as it may, the manipulation results must be viewed as preliminary, providing a suggestion to guide future studies.

It is also important to note that increased SFS activation with executive demand adds further support to the notion that activations in this region are not related simply to increased demand for eye and hand movement. These findings complement those of other researchers that have separated WM maintenance effects in this region from stimulus encoding and retrieval processes, using event-related fMRI (e.g., Courtney et al., 1996; Courtney, Ungerleider, Keil, \& Haxby, 1997; Haxby, Petit, Ungerleider, \& Courtney, 2000).

BA 10, in the anterior PFC, was the only region to show increases in manipulation across both hemispheres. BA 10 activation has been related in the literature on executive function to the switching of attention between percepts (Pollmann, 2001), subgoal processing (Braver $\&$ Bongiolatti, 2002), and tonic activity relating to increased demand for selective attention in a Stroop-like task (Wager et al., 2002).

Selective attention effects. Selective attention, but not any other executive process, produced more frequent activations in BA 32, in the medial PFC, in both BA and cluster analyses. Activations in the medial PFC, including the anterior cingulate, the medial supplementary motor area (SMA), and the pre-SMA, have been frequently reported in both simple storage and executive function tasks ( $\sim 40 \%$ probability of activation in storage only in BA 32, $\sim 60 \%$ probability of activation in the medial prefrontal cluster; Figure 2).

One important issue in the analysis of medial prefrontal activations is its high degree of functional heterogeneity (Devinsky, Morrell, \& Vogt, 1995; Picard \& Strick, 1996). Neither the Brodmann analysis nor the cluster analysis separated posterior from anterior medial prefrontal regions, which is an important distinction in the WM literature (e.g., Petit, Courtney, Ungerleider, \& Haxby, 1998). Together, the findings on selective attention (1-D vs. 2-D stimuli), the high rate of activation in simple storage tasks, and the lack of additional activation in executive function suggest that the medial PFC is activated by basic attention processes, such as selective attention. This interpretation leaves open the possibility that executive processes may produce quantitative increases in the amount of activation, as has been found in other studies (Fan, Flombaum, McCandliss, Thomas, \& Posner, 2003; Sylvester et al., 2003).

Another region of the brain that has been heavily implicated in selective attention, but which showed a quite different pattern of results in our analysis, is the parietal cortex. The superior parietal cortex (BA 7) was the only BA showing significant effects of executive function in each of continuous updating, order memory, and manipulation (Figure 3) and significant effects of executive function for all three types of storage material separately (Figure 6). Since this region has been consistently implicated in spatial and nonspatial attention tasks (Cabeza \& Nyberg, 2000; Smith \& Jonides, 1999), one plausible role for this area is as a mediator of basic control over the focus of attention. Whereas BA 10 and the DLPFC may be involved in establishing a task-related selection bias, the parietal cortex may play a role in implementing the bias.

The pattern of executive process activation in BA 7 contrasts with the pattern in BA 32 of selective attention effects but a lack of executive specialization. Although both 
regions appear to be involved in basic attentional processes, one idea is that basic processes in BA 7 (related, e.g., to coordinate transformation and shifting attentional allocation) may be used more frequently or intensely with executive demand, whereas those in BA 32 (related, e.g., to selective attention processes used to maintain focus on the relevant stimulus dimension) are used during task performance but are not additionally recruited with executive demand. Other interpretations exist. We propose this one as a speculation that may be tested further in future studies.

Our results suggest that activation in BA 7 is more frequent in spatial than in nonspatial tasks in simple storage, but this difference is not present when executive functions are required. This finding parallels the finding of left lateralization of verbal WM only in simple storage. The results implicate the parietal cortex in a general attentional role that extends beyond control of spatial attention and control of eye movements.

\section{Limitations of Meta-Analysis}

Several caveats must be raised about findings from this type of meta-analysis. One is that, as has been mentioned, large areas of activation are reduced to a single or several peak coordinates, which are then likely to have high spatial variability across studies. Although large activations in general have low spatial precision, this tendency may prevent findings that are robust in individual studies from being significant in the meta-analysis. A second concern is ceiling effects: Quantitative differences in activation in individual studies may not translate into higher reported frequencies in the meta-analysis, particularly if activation in the control condition is also high. These concerns are raised in addition to problems involving inconsistent analysis methods and reporting thresholds, which have been discussed elsewhere (Phan et al., 2002; Wager et al., 2003). We view this type of meta-analysis as an important tool that provides a synthesis across individual studies, which may be useful in testing existing hypotheses and developing new ones. However, we emphasize that meta-analysis provides a perspective that complements but does not replace the interpretation of results from individual studies.

\section{CONCLUSIONS}

WM tasks as a whole have produced a consistent set of activation sites in many brain regions. Our results suggest that WM representations in the frontal cortex are organized by process, rather than by material type. Systematic differences in material type are limited largely to the posterior part of the brain, which shows a clear spatial-ventral distinction between object and spatial memory, with the exception of object specialization in the right PFC. Executive demand produces reliable activations in regions largely in the frontal cortex but also quite consistently in the superior parietal cortex. Our results suggest that tasks requiring continuous updating and order memory involve more superior frontal cortex than do tasks requiring operations on WM items or dual tasking. Increasing processing demand similarly affects lateralization in the frontal cortex, producing bilateral activations in verbal storage and greater right lateralization in spatial storage.

To date, neuroimaging studies have used variants of several common tasks, most of which require multiple executive processes. However, across studies, there is evidence that executive functions may be fractionated into different component processes. One class is manipulation of information in WM, which may involve mental operations, switching, and inhibition. This class most frequently activates the inferior frontal cortex. A second class is sequential updating and prioritization of information in WM, reflected here in the constructs of continuous updating and temporal order memory. This class most frequently activates the superior frontal cortex. More studies are needed that manipulate subcomponents of executive processes individually, particularly studies that involve manipulation of information in WM while controlling other executive requirements.

\section{REFERENCES}

Aldridge, J. W., \& BerRidge, K. C. (1998). Coding of serial order by neostriatal neurons: A "natural action" approach to movement sequence. Journal of Neuroscience, 18, 2777-2787.

BADDELEY, A. (1992). Working memory. Science, 255, 556-559.

Barch, D. M., Braver, T. S., Nystrom, L. E., Forman, S. D., Noll, D. C., \& Cohen, J. D. (1997). Dissociating working memory from task difficulty in human prefrontal cortex. Neuropsychologia, 35, 1373-1380.

Belger, A., Puce, A., Krystal, J. H., Gore, J. C., Goldman-Rakic, P., \& MCCARTHY, G. (1998). Dissociation of mnemonic and perceptual processes during spatial and nonspatial working memory using fMRI. Human Brain Mapping, 6, 14-32.

Berman, R. A., \& COLBY, C. L. (2002). Spatial working memory in human extrastriate cortex. Physiology \& Behavior, 77, 621-627.

Bor, D., DunCAN, J., \& OWEN, A. M. (2001). The role of spatial configuration in tests of working memory explored with functional neuroimaging. Scandinavian Journal of Psychology, 42, 217-224.

Braver, T. S., BArch, D. M., Kelley, W. M., Buckner, R. L., Cohen, N. J., MieZin, F. M., SNyder, A. Z., Ollinger, J. M., AkbudAK, E., Conturo, T. E., \& Petersen, S. E. (2001). Direct comparison of prefrontal cortex regions engaged by working and long-term memory tasks. NeuroImage, 14, 48-59.

Braver, T. S., \& Bongiolatti, S. R. (2002). The role of frontopolar cortex in subgoal processing during working memory. NeuroImage, 15, 523-536.

Braver, T. S., Cohen, J. D., Nystrom, L. E., Jonides, J., Smith, E. E., \& Noll, D. C. (1997). A parametric study of prefrontal cortex involvement in human working memory. Neurolmage, 5, 49-62.

Bunge, S. A., KlingberG, T., JacobSen, R. B., \& GAbrieli, J. D. (2000). A resource model of the neural basis of executive working memory. Proceedings of the National Academy of Sciences, 97, 3573-3578.

CABEZA, R., \& NYBERG, L. (2000). Imaging cognition II: An empirical review of 275 PET and fMRI studies. Journal of Cognitive Neuroscience, 12, 1-47.

Callicott, J. H., Mattay, V. S., Bertolino, A., Finn, K., Coppola, R., Frank, J. A., GoldberG, T. E., \& Weinberger, D. R. (1999). Physiological characteristics of capacity constraints in working memory as revealed by functional MRI. Cerebral Cortex, 9, 20-26.

CARTER, C. S., Braver, T. S., Barch, D. M., Botvinick, M. M., Noll, D., \& COHEN, J. D. (1998). Anterior cingulate cortex, error detection, and the online monitoring of performance. Science, 280, 747-749. 
Casey, B. J., Cohen, J. D., O'Craven, K., Davidson, R. J., Irwin, W., Nelson, C. A., Noll, D. C., Hu, X., Lowe, M. J., Rosen, B. R., TRUWITT, C. L., \& Turski, P. A. (1998). Reproducibility of fMRI results across four institutions using a spatial working memory task. Neurolmage, 8, 249-261.

Chein, J. M., \& FiEZ, J. A. (2001). Dissociation of verbal working memory system components using a delayed serial recall task. Cerebral Cortex, 11, 1003-1014.

Chein, J. M., Fissell, K., JACOBS, S., \& FieZ, J. A. (2002). Functional heterogeneity within Broca's area during verbal working memory. Physiology \& Behavior, 77, 635-639.

Clark, C. R., Egan, G. F., McFarlane, A. C., Morris, P., Weber, D., Sonkkilla, C., Marcina, J., \& Tochon-Danguy, H. J. (2000). Updating working memory for words: A PET activation study. Human Brain Mapping, 9, 42-54.

Cohen, J. D., Dunbar, K., \& MCClelland, J. L. (1990). On the control of automatic processes: A parallel distributed processing account of the Stroop effect. Psychological Review, 97, 332-361

Cohen, J. D., Perlstein, W. M., Braver, T. S., Nystrom, L. E., Noll, D. C., Jonides, J., \& SMITH, E. E. (1997). Temporal dynamics of brain activation during a working memory task. Nature, 386, 604-608.

Colby, C. L., \& GoldberG, M. E. (1999). Space and attention in parietal cortex. Annual Review of Neuroscience, 22, 319-349.

Collette, F., Salmon, E., Van der linden, M., Chicherio, C., Belleville, S., Degueldre, C., Delfiore, G., \& Franck, G. (1999). Regional brain activity during tasks devoted to the central executive of working memory. Cognitive Brain Research, 7, 411-417.

Cornette,L., Dupont, P., Bormans, G., Mortelmans, L., \& Orban, G. A. (2001). Separate neural correlates for the mnemonic components of successive discrimination and working memory tasks. Cerebral Cortex, 11, 59-72.

Cornette, L., Dupont, P., Salmon, E., \& Orban, G. A. (2001). The neural substrate of orientation working memory. Journal of Cognitive Neuroscience, 13, 813-828.

Courtney, S. M., Petit, L., Haxby, J. V., \& Ungerleider, L. G. (1998). The role of prefrontal cortex in working memory: Examining the contents of consciousness. Philosophical Transactions of the Royal Society of London: Series B, 353, 1819-1828.

Courtney, S. M., Ungerleider, L. G., Keil, K., \& Haxby, J. V. (1996). Object and spatial visual working memory activate separate neural systems in human cortex. Cerebral Cortex, 6, 39-49.

Courtney, S. M., Ungerleider, L. G., Keil, K., \& Haxby, J. V. (1997). Transient and sustained activity in a distributed neural system for human working memory. Nature, 386, 608-611.

Crosson, B., Rao, S. M., Woodley, S. J., Rosen, A. C., Bobholz, J. A., Mayer, A., Cunningham, J. M., Hammeke, T. A., Fuller, S. A., Binder, J. R., CoX, R. W., \& Stein, E. A. (1999). Mapping of semantic, phonological, and orthographic verbal working memory in normal adults with functional magnetic resonance imaging. Neuropsychology, 13, 171-187.

CurTis, C. E., ZALD, D. H., \& PARDo, J. V. (2000). Organization of working memory within the human prefrontal cortex: A PET study of selfordered object working memory. Neuropsychologia, 38, 1503-1510.

Dade, L. A., Zatorre, R. J., Evans, A. C., \& Jones-Gotman, M. (2001). Working memory in another dimension: Functional imaging of human olfactory working memory. NeuroImage, 14, 650-660.

De Fockert,J. W., Rees, G., Frith, C. D., \& LAVIE, N. (2001). The role of working memory in visual selective attention. Science, 291, 18031806.

D'Esposito, M., Aguirre, G. K., Zarahn, E., Ballard, D., Shin, R. K., \& LEASE, J. (1998). Functional MRI studies of spatial and nonspatial working memory. Cognitive Brain Research, 7, 1-13.

D’Esposito, M., Postle, B. R., Jonides, J., \& Smith, E. E. (1999). The neural substrate and temporal dynamics of interference effects in working memory as revealed by event-related functional MRI. Proceedings of the National Academy of Sciences, 96, 7514-7519.

De vinsky, O., Morrell, M. J., \& Vogt, B. A. (1995). Contributions of anterior cingulate cortex to behaviour. Brain, 118(Pt. 1), 279-306.

Diwadkar, V. A., CARPenter, P. A., \& Just, M. A. (2000). Collaborative activity between parietal and dorso-lateral prefrontal cortex in dynamic spatial working memory revealed by fMRI. NeuroImage, 12, 85-99.

Druzgal, T. J., \& D'Esposito, M. (2001). Activity in fusiform face area modulated as a function of working memory load. Cognitive Brain Research, 10, 355-364.

Fan, J., Flombaum, J. I., MCCandliss, B. D., Thomas, K. M., \& PosNER, M. I. (2003). Cognitive and brain consequences of conflict. Neurolmage, 18, 42-57.

Funahashi, S., Bruce, C. J., \& Goldman-Rakic, P. S. (1989). Mnemonic coding of visual space in the monkey's dorsolateral prefrontal cortex. Journal of Neurophysiology, 61, 331-349.

Funahashi, S., Chafee, M. V., \& Goldman-Rakic, P. S. (1993). Prefrontal neuronal activity in rhesus monkeys performing a delayed anti-saccade task. Nature, 365, 753-756.

Grady, C. L., Mcintosh, A. R., Bookstein, F., Horwitz, B., RAPOPORT, S. I., \& HAXBY, J. V. (1998). Age-related changes in regional cerebral blood flow during working memory for faces. NeuroImage, 8, 409-425.

Haut, M. W., Leach, S., Kuwabara, H., Whyte, S., Callahan, T., DuCATMAN, A., Lombardo, L. J., \& GUPTA, N. (2000). Verbal working memory and solvent exposure: A positron emission tomography study. Neuropsychology, 14, 551-558.

Haxby, J. V., Petit, L., Ungerleider, L. G., \& Courtney, S. M. (2000). Distinguishing the functional roles of multiple regions in distributed neural systems for visual working memory. NeuroImage, 11(5, Pt. 1), 380-391.

Honey, G. D., Bullmore, E. T., \& Sharma, T. (2000). Prolonged reaction time to a verbal working memory task predicts increased power of posterior parietal cortical activation. Neurolmage, 12, 495-503.

Jiang, Y., Haxby, J. V., Martin, A., Ungerleider, L. G., \& PARASURAMAN, R. (2000). Complementary neural mechanisms for tracking items in human working memory. Science, 287, 643-646.

Jonides, J., BAdre, D., Curtis, C., Thompson-Schill, S., \& Smith, E. E. (2002). Mechanisms of conflict resolution in the prefrontal cortex. In D. T. Stuss \& R. L. Knight (Eds.), The frontal lobes (pp. 233-245). Oxford: Oxford University Press.

Jonides, J., Schumacher, E. H., Smith, E. E., Koe PPE, R. A., Awh, E., Reuter-Lorenz, P. A., Marshuetz, C., \& Willis, C. R. (1998). The role of parietal cortex in verbal working memory. Journal of Neuroscience, 18, 5026-5034.

Jonides, J., Smith, E. E., Koeppe, R. A., Awh, E., Minoshima, S., \& Mintun, M. A. (1993). Spatial working memory in humans as revealed by PET. Nature, 363, 623-625.

Jonides, J., Smith, E. E., Marshuetz, C., Koeppe, R. A., \& ReuterLORENZ, P. A. (1998). Inhibition in verbal working memory revealed by brain activation. Proceedings of the National Academy of Sciences, 95, 8410-8413.

Kaufman, L., \& Rousseeuw, P. J. (1987). Clustering by means of medoids. In Y. Dodge (Ed.), Statistical data analysis based on the L1 norm (pp. 405-416). Amsterdam: North-Holland.

KAufMAN, L., \& RousseEuW, P. J. (1990). Finding groups in data. New York: Wiley.

Klingberg, T., O'Sullivan, B. T., \& Roland, P. E. (1997). Bilateral activation of fronto-parietal networks by incrementing demand in a working memory task. Cerebral Cortex, 7, 465-471.

LaBar, K. S., Gitelman, D. R., Parrish, T. B., \& Mesulam, M. (1999). Neuroanatomic overlap of working memory and spatial attention networks: A functional MRI comparison within subjects. NeuroImage, 10, 695-704.

Landro, N. I., Rund, B. R., Lund, A., Sundet, K., Muellem, N., AsBJornsen, A., Thomsen, T., ERsland, L., Lundervold, A., SMIE VOlL, A. I., Egeland, J., Stordal, K., Roness, A., SundberG, H., \& HugDAHL, K. (2001). Honig's model of working memory and brain activation: An fMRI study. NeuroReport, 12, 4047-4054.

LEVY, R., \& GOLDMAN-RAKIC,P. S. (1999). Association of storage and processing functions in the dorsolateral prefrontal cortex of the nonhuman primate. Journal of Neuroscience, 19, 5149-5158.

MACQUEEN, J. B. (1967). Some methods for classification and analysis of multivariate observations. Paper presented at the 5th Berkeley Symposium on Mathematical Statistics and Probability. 
Marshuetz, C., Smith, E. E., Jonides, J., DeGutis, J., \& ChenevERT, T. L. (2000). Order information in working memory: fMRI evidence for parietal and prefrontal mechanisms. Journal of Cognitive Neuroscience, 12(Suppl. 2), 130-144.

McCarthy, G., Puce, A., Constable, R. T., Krystal, J. H., Gore, J. C., \& GoldMAN-RAKIC, P. (1996). Activation of human prefrontal cortex during spatial and nonspatial working memory tasks measured by functional MRI. Cerebral Cortex, 6, 600-611.

Mecklinger, A., Bosch, V., Gruenewald, C., Bentin, S., \& von Cramon, D. Y. (2000). What have Klingon letters and faces in common? An fMRI study on content-specific working memory systems. Human Brain Mapping, 11, 146-161.

Miller, E. K., \& COHEN, J. D. (2001). An integrative theory of prefrontal cortex function. Annual Review of Neuroscience, 24, 167-202.

Mitche Ll, K. J., Johnson, M. K., RAYE, C. L., \& D'EsPosito, M. (2000). fMRI evidence of age-related hippocampal dysfunction in feature binding in working memory. Cognitive Brain Research, 10, 197-206.

Miyake, A., Friedman, N. P., Emerson, M. J., Witzki, A. H., \& HowERTER, A. (2000). The unity and diversity of executive functions and their contributions to complex "frontal lobe" tasks: A latent variable analysis. Cognitive Psychology, 41, 49-100.

Nystrom, L. E., Braver, T. S., SabB, F. W., Delgado, M. R., Noll, D. C., \& CoHEN, J. D. (2000). Working memory for letters, shapes, and locations: fMRI evidence against stimulus-based regional organization in human prefrontal cortex. NeuroImage, 11(5, Pt. 1), 424-446.

OWEN, A. M. (1997). The functional organization of working memory processes within human lateral frontal cortex: The contribution of functional neuroimaging. European Journal of Neuroscience, 9, 1329-1339.

OWEN, A. M. (2000). The role of the lateral frontal cortex in mnemonic processing: The contribution of functional neuroimaging. Experimental Brain Research, 133, 33-43.

Owen, A. M., Evans, A. C., \& Petrides, M. (1996). Evidence for a two-stage model of spatial working memory processing within the lateral frontal cortex: A positron emission tomography study. Cerebral Cortex, 6, 31-38.

Owen, A. M., Herrod, N. J., Menon, D. K., Clark, J. C., Downey, S. P., Carpenter, T. A., Minhas, P. S., Turkhe imer, F. E., Williams, E. J., Robbins, T. W., Sahakian, B. J., Petrides, M., \& Pickard, J. D. (1999). Redefining the functional organization of working memory processes within human lateral prefrontal cortex. European Journal of Neuroscience, 11, 567-574.

Owen, A. M., Stern, C. E., Look, R. B., Tracey, I., Rosen, B. R., \& PETRIDES, M. (1998). Functional organization of spatial and nonspatial working memory processing within the human lateral frontal cortex. Proceedings of the National Academy of Sciences, 95, 7721-7726.

Paulesu, E., Frith, C. D., \& Frackowiak, R. S. (1993). The neural correlates of the verbal component of working memory. Nature, $\mathbf{3 6 2}$, 342-345.

Perlstein, W. M., Elbert, T., \& Stenger, V. A. (2002). Dissociation in human prefrontal cortex of affective influences on working memoryrelated activity. Proceedings of the National Academy of Sciences, 99, 1736-1741.

Petit, L., Courtney, S. M., Ungerleider, L. G., \& Haxby, J. V. (1998). Sustained activity in the medial wall during working memory delays. Journal of Neuroscience, 18, 9429-9437.

Petrides, M. (1991). Functional specialization within the dorsolateral frontal cortex for serial order memory. Proceedings of the Royal Society of London: Series B, 246, 299-306.

Petrides, M., Alivisatos, B., Meyer, E., \& Evans, A. C. (1993). Functional activation of the human frontal cortex during the performance of verbal working memory tasks. Proceedings of the National Academy of Sciences, 90, 878-882.

Phan, K. L., Wager, T., TAYlor, S. F., \& Liberzon, I. (2002). Functional neuroanatomy of emotion: A meta-analysis of emotion activation studies in PET and fMRI. NeuroImage, 16, 331-348.

PICARD, N., \& STRICK, P. L. (1996). Motor areas of the medial wall: A review of their location and functional activation. Cerebral Cortex, $\mathbf{6}$, 342-353.

PollmanN, S. (2001). Switching between dimensions, locations, and responses: The role of the left frontopolar cortex. NeuroImage, 14(1, Pt. 2), S118-S124.

PollmanN, S., \& VON CRAMON, D. Y. (2000). Object working memory and visuospatial processing: Functional neuroanatomy analyzed by event-related fMRI. Experimental Brain Research, 133, 12-22.

RAMA, P., MARTINKAUPPI, S., LinNANKoski, I., KoIvisto, J., ARONEN, H. J., \& CARLSON, S. (2001). Working memory of identification of emotional vocal expressions: An fMRI study. NeuroImage, 13(6, Pt. 1), 1090-1101.

Reuter-Lorenz, P. A., Jonides, J., Smith, E. E., Hartley, A., Miller, A., Marshue TZ, C., \& Koepre, R. A. (2000). Age differences in the frontal lateralization of verbal and spatial working memory revealed by PET. Journal of Cognitive Neuroscience, 12, 174-187. RoCKLAND, K. S. (2002). Visual cortical organization at the single axon level: A beginning. Neuroscience Research, 42, 155-166.

Rowe, J. B., \& PAssingham, R. E. (2001). Working memory for location and time: Activity in prefrontal area 46 relates to selection rather than maintenance in memory. NeuroImage, 14(1, Pt. 1), 77-86.

Rubenstein, J. S., Meyer, D. E., \& Evans, J. E. (2001). Executive control of cognitive processes in task switching. Journal of Experimental Psychology: Human Perception \& Performance, 27, 763-797.

Rypma, B., Prabhakaran, V., Desmond, J. E., Glover, G. H., \& GABRIELI, J. D. (1999). Load-dependent roles of frontal brain regions in the maintenance of working memory. NeuroImage, 9, 216-226.

Schumacher, E. H., LAuber, E., Awh, E., Jonides, J., SMith, E. E., \& KoEPPE, R. A. (1996). PET evidence for an amodal verbal working memory system. NeuroImage, 3, 79-88.

Smith, E. E., Geva, A., Jonides, J., Miller, A., Reuter-Lorenz, P., \& KoEPPE, R. A. (2001). The neural basis of task-switching in working memory: Effects of performance and aging. Proceedings of the National Academy of Sciences, 98, 2095-2100.

SMith, E. E., \& JoNidES, J. (1999). Storage and executive processes in the frontal lobes. Science, 283, 1657-1661.

SMith, E. E., \& JONIDES, J. (2003). Executive control and thought. In L. R. Squire (Ed.), Fundamental neuroscience (2nd ed., pp. 13771394). San Diego: Academic Press.

Smith, E. E., Jonides, J., \& KoE PPE, R. A. (1996). Dissociating verbal and spatial working memory using PET. Cerebral Cortex, 6, 11-20. Smith, E. E., Jonides, J., Koe PPE, R. A., Awh, E., Schumacher, E. H., \& Minoshima, S. (1995). Spatial versus object working-memory: PET investigations. Journal of Cognitive Neuroscience, 7, 337-356.

Smith, E. E., Jonides, J., Marshuetz, C., \& KoepPe, R. A. (1998). Components of verbal working memory: Evidence from neuroimaging. Proceedings of the National Academy of Sciences, 95, 876882.

Stern, C. E., Owen, A. M., Tracey, I., Look, R. B., Rosen, B. R., \& Petrides, M. (2000). Activity in ventrolateral and mid-dorsolateral prefrontal cortex during nonspatial visual working memory processing: Evidence from functional magnetic resonance imaging. NeuroImage, 11(5, Pt. 1), 392-399.

Sylvester, C. Y., Wager, T. D., Lacey, S. C., Hernande Z, L., Nichols, T. E., SMith, E. E., \& Jonides, J. (2003). Switching attention and resolving interference: fMRI measures of executive functions. Neuropsychologia, 41, 357-370.

Thomas, K. M., King, S. W., Franzen, P. L., Welsh, T. F., Berkowitz, A. L., Noll, D. C., Birmaher, V., \& CASEy, B. J. (1999). A developmental functional MRI study of spatial working memory. NeuroImage, 10(3, Pt. 1), 327-338.

Tsukiura, T., Fuji, T., Takahashi, T., Xiao, R., Inase, M., IJjima, T., YAMADORI, A., \& OKUDA, J. (2001). Neuroanatomical discrimination between manipulating and maintaining processes involved in verbal working memory: A functional MRI study. Cognitive Brain Research, 11, 13-21.

UNGERLEIDER,L. G., \& HAXBY, J. V. (1994). "What" and "where" in the human brain. Current Opinion in Neurobiology, 4, 157-165.

Van der linden, M., Collette, F., Salmon, E., Delfiore, G., Degueldre, C., LuXen, A., \& Franck, G. (1999). The neural correlates of updating information in verbal working memory. Memory, 7, 549-560.

Wager, T. D., Jonides, J., Smith, E. E., Hernande Z, L., Bryck, R., 
Nichols, T. E., Sylvester, C. C., LACEY, S. C., \& Noll, D. C. (2002, April). Response conflict and cognitive control: Item and set-related processes in a Stroop-like task. Poster presented at the Annual Meeting of the Cognitive Neuroscience Society, San Francisco.

WAger, T. D., Phan, K. L., Liberzon, I., \& TAYlor, S. F. (2003). Valence, gender, and lateralization of functional brain anatomy in emotion: A meta-analysis of findings from neuroimaging. NeuroImage, 19, 513-531.

Wilson, F. A., SCAlaidhe, S. P., \& Goldman-RAKic, P. S. (1993). Dissociation of object and spatial processing domains in primate prefrontal cortex. Science, 260, 1955-1958.

Zurowski, B., Gostomzyk, J., Gron, G., Weller, R., Schirrmeister, H., Neumeier, B., Spitzer, M., Reske, S. N., \& Walter, H. (2002). Dissociating a common working memory network from different neural substrates of phonological and spatial stimulus processing. NeuroImage, 15, 45-57.

\section{NOTES}

1. Negative values in some regions are to be expected because of the normalization by the total number of studies/peaks. Thus, negative values cannot be interpreted as indicating that a region is more active for passive storage than for executive function tasks; rather, it indicates that the distribution of peaks for executive processes is relatively less concentrated in that region.

2. This report uses the anatomical boundaries of the primary visual cortex (BA 17) from the Talairach Daemon atlas. Imprecision in defining the boundaries of this region and normalization procedures across studies make the exact boundaries uncertain.

(Manuscript received April 25, 2003; revision accepted for publication October 1, 2003.) 